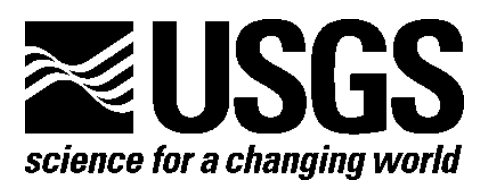

Geographic Analysis and Monitoring Program

\title{
Social Values for Ecosystem Services (SoIVES): A GIS Application for Assessing, Mapping, and Quantifying the Social Values of Ecosystem Services-Documentation and User Manual, Version 1.0
}

By Benson C. Sherrouse, ${ }^{1}$ Jodi L. Riegle, ${ }^{1}$ and Darius J. Semmens ${ }^{1}$

1U.S. Geological Survey, Rocky Mountain Geographic Science Center, Denver, Colo.

Open-File Report 2010-1219

U.S. Department of the Interior

U.S. Geological Survey 


\section{U.S. Department of the Interior \\ KEN SALAZAR, Secretary}

\section{U.S. Geological Survey \\ Marcia K. McNutt, Director}

U.S. Geological Survey, Reston, Virginia: 2010

For product and ordering information:

World Wide Web: http://www.usgs.gov/pubprod

Telephone: 1-888-ASK-USGS

For more information on the USGS-the Federal source for science about the Earth, its natural and living resources, natural hazards, and the environment:

World Wide Web: http://www.usgs.gov

Telephone: 1-888-ASK-USGS

Suggested citation:

Sherrouse, B.C., Riegle, J.L., and Semmens, D.J., 2010, Social values for ecosystem services (SolVES): A GIS application for assessing, mapping, and quantifying the social values of ecosystem services-Documentation and user manual, version 1.0: U.S. Geological Survey Open-File Report 2010-1219, 44 p.

Any use of trade, product, or firm names is for descriptive purposes only and does not imply endorsement by the U.S. Government.

Although this report is in the public domain, permission must be secured from the individual copyright owners to reproduce any copyrighted material contained within this report. 


\section{Contents}

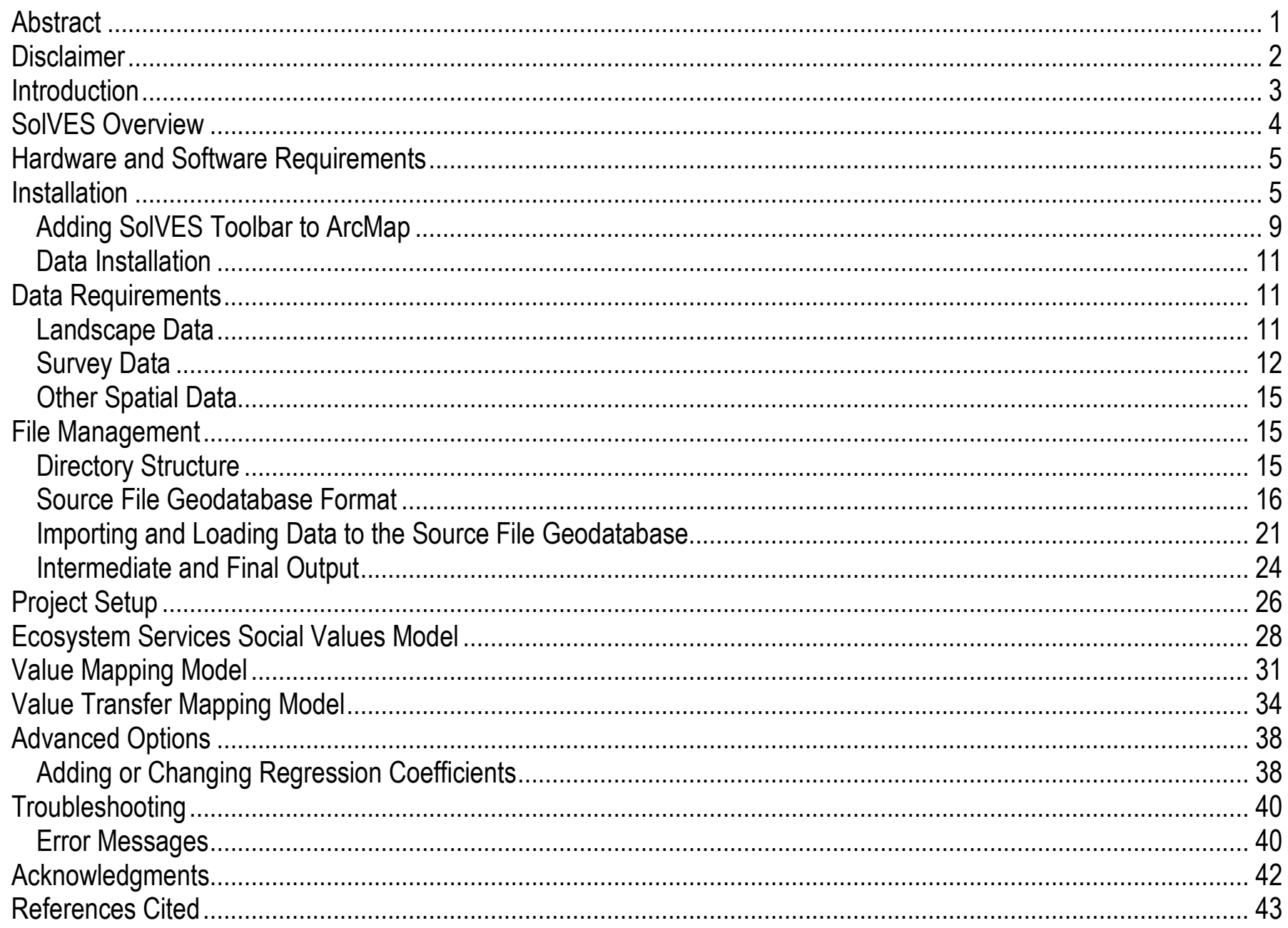

\section{Figures}

Figure 1. General process flow of SolVES' Ecosystem Services Social Values and Value Mapping Models ..... 4

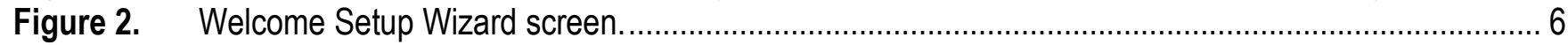

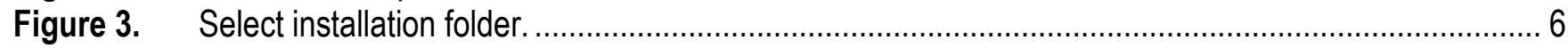

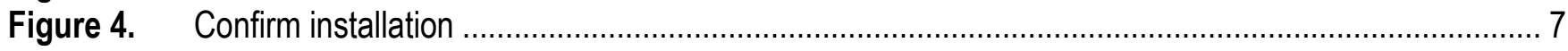

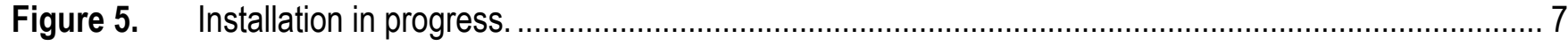

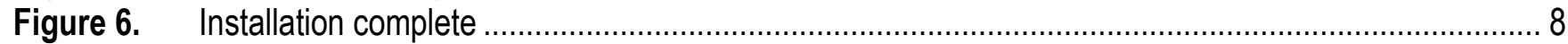

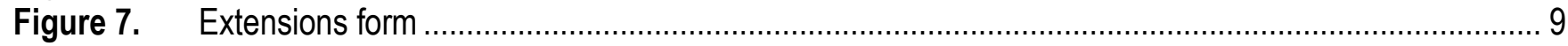

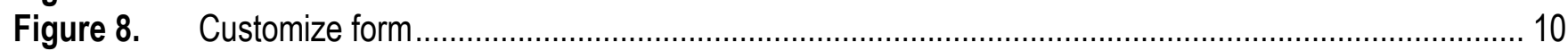

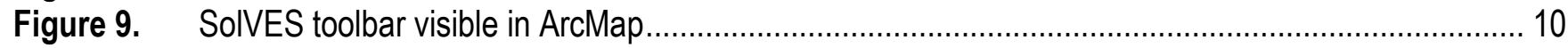

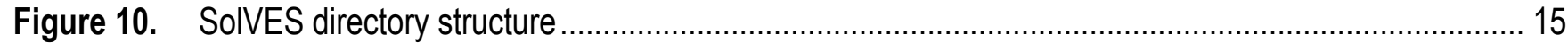

Figure 11. Overview of the Eco_Soc_Values.gdb source file geodatabase ................................................... 16

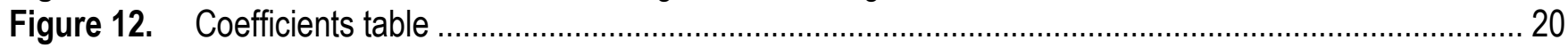

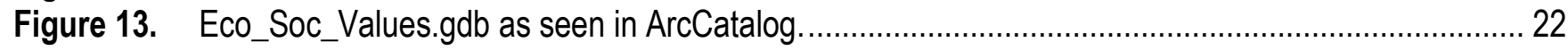




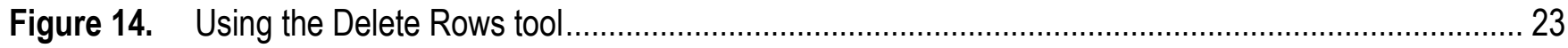

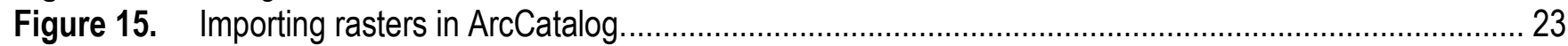

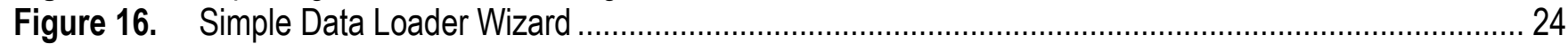

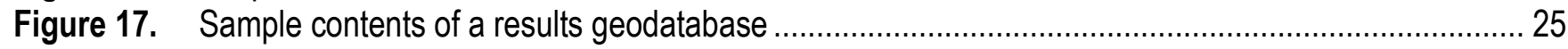

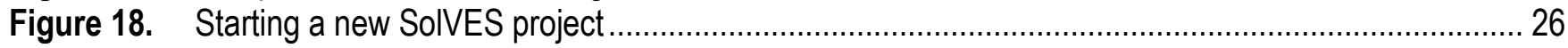

Figure 19. Navigating to the Home Directory from the Project Setup form................................................... 26

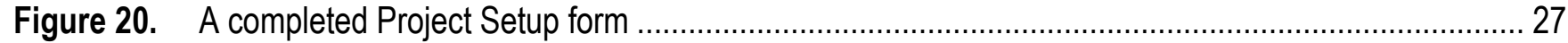

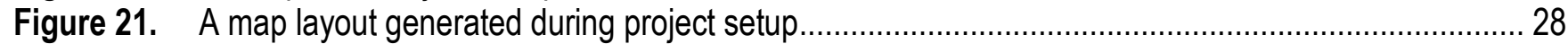

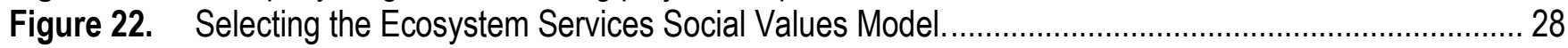

Figure 23. Parameter selection form for the Ecosystem Services Social Values Model. .................................... 29

Figure 24. Ecosystem Services Social Values Model process steps ........................................................... 30

Figure 25. Average nearest neighbor statistics calculated by the Ecosystem Services Social Values Model..... 31

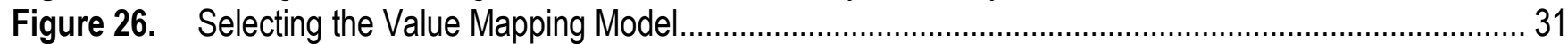

Figure 27. Parameter selection form for the Value Mapping Model ............................................................. 32

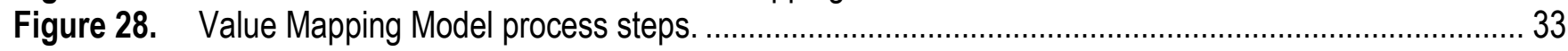

Figure 29. Sample output from the Value Mapping Model ………........................................................... 34

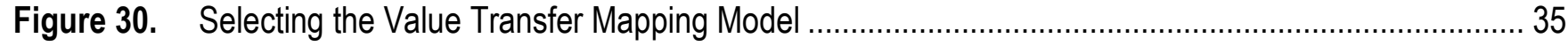

Figure 31. Parameter selection form for the Value Transfer Mapping Model ................................................ 35

Figure 32. Value Transfer Mapping Model process steps.......................................................................... 36

Figure 33. Sample output from the Value Transfer Mapping Model.............................................................. 37

Figure 34. Improper selection of model parameters error message............................................................... 40

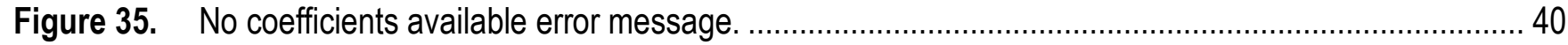

\section{Tables}

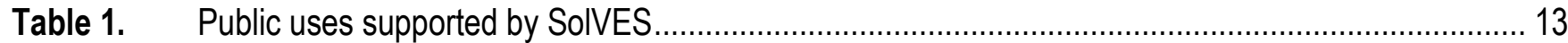

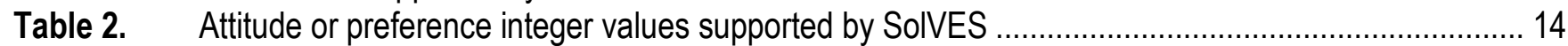

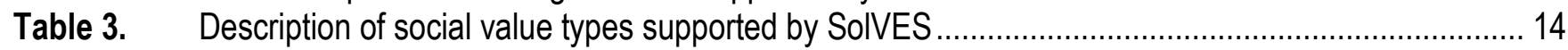

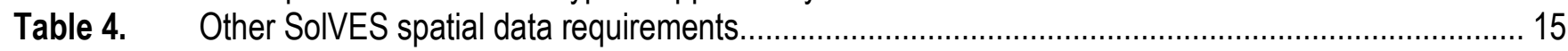

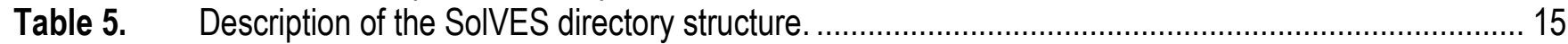

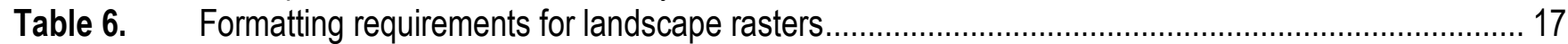

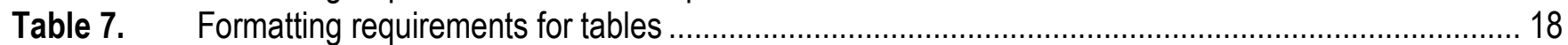

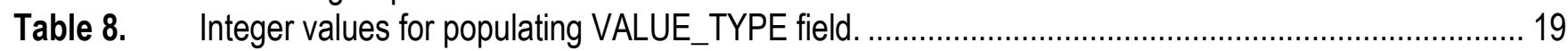

Table 9. Tables not requiring user preparation or interaction................................................................. 19

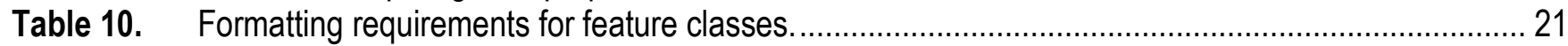

Table 11. Formatting requirements for the Coefficients table. .................................................................. 38 


\title{
Social Values for Ecosystem Services (SoIVES): A GIS Application for Assessing, Mapping, and Quantifying the Social Values of Ecosystem Services-Documentation and User Manual, Version 1.0
}

By Benson C. Sherrouse, Jodi L. Riegle, and Darius J. Semmens

\begin{abstract}
In response to the need for incorporating quantified and spatially explicit measures of social values into ecosystem services assessments, the Rocky Mountain Geographic Science Center, in collaboration with Colorado State University, has developed a geographic information system application, Social Values for Ecosystem Services (SolVES). SolVES can be used to assess, map, and quantify the perceived social values of ecosystem services. SolVES derives a quantitative social values metric, the Value Index, from a combination of spatial and nonspatial responses to public attitude and preference surveys. SolVES also generates landscape metrics, such as average elevation and distance to water, calculated from spatial data layers describing the underlying physical environment. Using kernel density calculations and zonal statistics, SolVES derives and maps the 10-point Value Index and reports landscape metrics associated with each index value for social value types such as aesthetics, biodiversity, and recreation. This can be repeated for various survey subgroups as distinguished by their attitudes and preferences regarding public uses of the forests such as motorized recreation and logging for fuels reduction. The Value Index provides a basis of comparison within and among survey subgroups to consider the effect of social contexts on the valuation of ecosystem services. SolVES includes regression coefficients linking the predicted value (the Value Index) to landscape metrics. These coefficients are used to generate predicted social value maps using value transfer techniques for areas where primary survey data are not available. SolVES was developed, and will continue to be enhanced through future versions, as a public domain tool to enable decision makers and researchers to map the social values of ecosystem services and to facilitate discussions among diverse stakeholders regarding tradeoffs between different ecosystem services in a variety of physical and social contexts.
\end{abstract}




\section{Disclaimer}

The SolVES tool described in this manual is applied at the user's own risk. The U.S. Department of the Interior, or the system authors can not assume responsibility for system operation, output, interpretation, or use. 


\section{Introduction}

Social Values for Ecosystem Services (SolVES) is a geographic information system (GIS) application for incorporating quantified and spatially explicit social values information into ecosystem services assessments. It was developed by the U.S. Geological Survey's (USGS) Rocky Mountain Geographic Science Center (RMGSC) in collaboration with Dr. Jessica Clement, at Colorado State University (CSU). SolVES addresses the need to account for differing values, attitudes, and preferences among diverse stakeholders in the analysis of tradeoffs among ecosystem services.

Ecosystem services provide both tangible and intangible benefits to human life (Daily, 1997). Whereas sometimes these benefits can be quantified in monetary terms, often they exist as public goods that bypass the economy (Costanza and others, 1997). Further, monetary values, even if available, are not always desirable as they can distract decision makers and stakeholders from the primary purpose of ecosystem management (USDA, 2008). Decision makers require estimates of social values beyond those defined economically to assess the full range of ecosystem values. These social values include sociocultural perceptions of human well-being derived from nature, measured using social assessments and other non-utilitarian means of capturing their value (Millennium Ecosystem Assessment, 2003; Cowling and others, 2008; Kumar and Kumar, 2008; Nijkamp and others, 2008). SolVES uses previous social values mapping research (Brown and Reed, 2000; Brown and others, 2002; Reed and Brown, 2003; Brown and others, 2004; Brown, 2005; Brown and Alessa, 2005; Alessa and others, 2008) to implement a methodology for incorporating social values into the ecosystem services assessment process by quantifying and representing these values across the landscape as a "Value Index," which provides a spatial, non-monetary metric statistically related to characteristics of the underlying physical environment.

SolVES provides functionality to assess, map, and quantify social values such as aesthetics, biodiversity, and recreation by deriving social value maps and modeling their relation to landscape metrics from a combination of spatial and nonspatial responses to stakeholder attitude and preference surveys along with various environmental data layers. SolVES also uses regression coefficients derived from these modeled relation to generate predicted social value maps for areas where primary survey data are not available by loosely following previous approaches using GIS for applying value transfer methods to ecosystem services valuation (Troy and Wilson, 2006). 


\section{SoIVES Overview}

SolVES is packaged as a custom toolbar for the Environmental Systems Research Institute's (ESRI's ${ }^{\circledR}$ ) ArcGIS 9.3 GIS software. It was developed using VB.NET. It uses geospatial and tabular data to parameterize three separate models: the Ecosystem Services Social Values Model, the Value Mapping Model, and the Value Transfer Mapping Model. The general process flow of the SolVES' Ecosystem Services Social Values and Value Mapping Models is shown below (fig. 1).

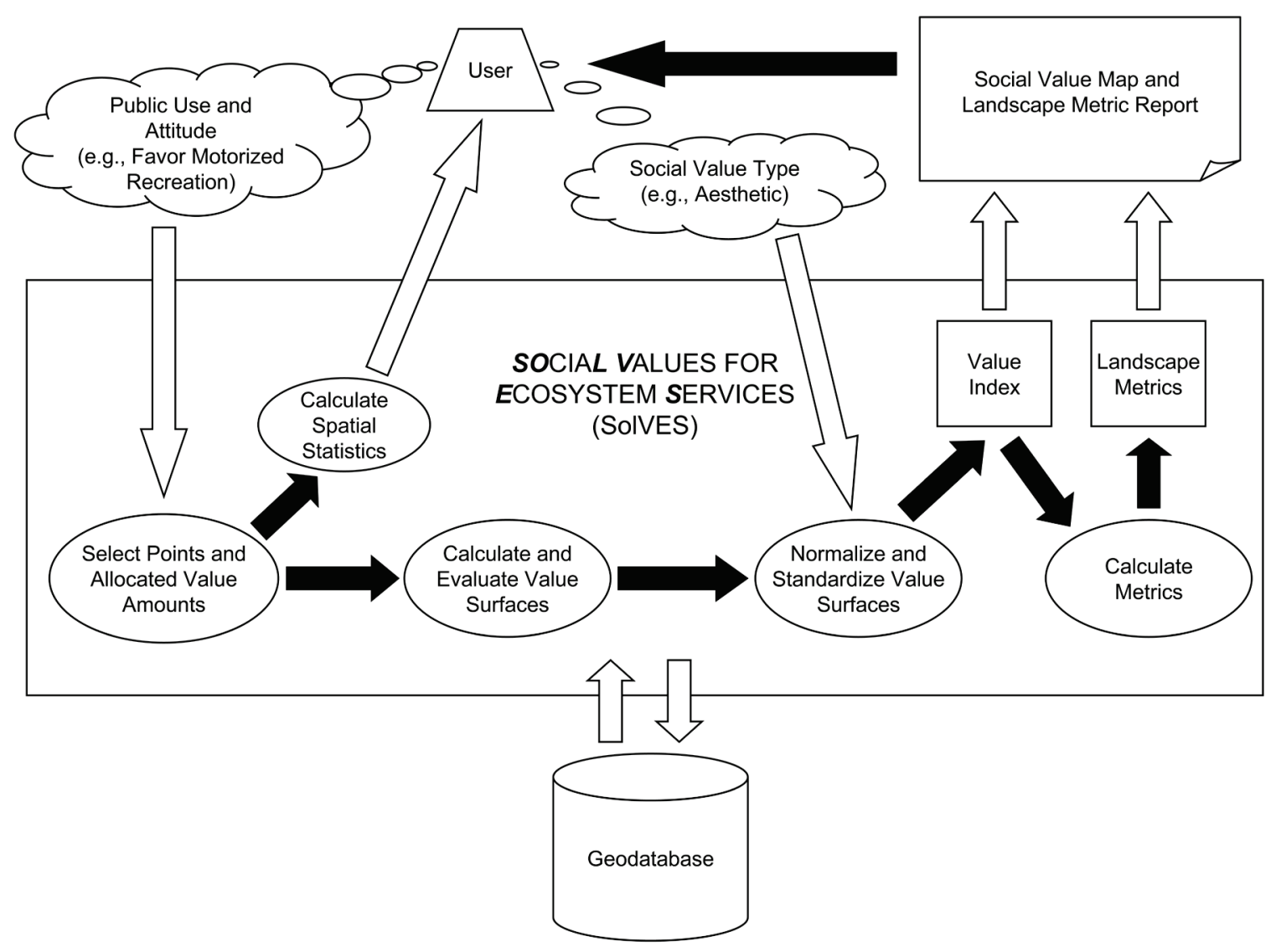

Figure 1. General process flow of SolVES' Ecosystem Services Social Values and Value Mapping Models.

The Ecosystem Services Social Values Model and the Value Mapping Model operate together in a sequence as follows (fig. 1):

1. The user starts the Ecosystem Services Social Values Model and selects a public use and an attitude or preference regarding that use.

2. Based on the user's selections, the model retrieves the matching survey response mapped points and value allocations.

3. Using the value allocations to weight the mapped points, the model calculates kernel density surfaces and spatial statistics for the mapped points associated with each of 12 social value types.

4. The model identifies the most highly valued social value type as well as the location it is most highly valued. 
5. The model completes processing and provides the user with average nearest neighbor statistics.

6. The user starts the Value Mapping Model and selects a social value type.

7. The model uses the most highly valued social value type to normalize the kernel density surface of the selected social value type and standardizes the calculated surface to produce the Value Index.

8. The model calculates landscape metrics using the Value Index surface and presents the Value Index map and landscape metrics to the user in a composite report.

The Value Transfer Mapping Model operates separately from the other models by relying on regression coefficients derived from primary survey data rather than survey data itself:

1. The user starts the Value Transfer Mapping Model and selects a public use, an attitude or preference regarding that use, and a social value type.

2. Based on the user's selections, the model retrieves the appropriate regression coefficients associated with each landscape data layer.

3. Using map algebra, the model applies the retrieved regression coefficients to their corresponding landscape data layers.

4. The model reclassifies the resulting surface to produce the Value Index.

5. The model calculates landscape metrics using the Value Index surface and presents the Value Index map and landscape metrics to the user in a composite report.

\section{Hardware and Software Requirements}

SolVES requires the ESRI® ArcGIS 9.3 software and the Spatial Analyst Extension for working with grid-based data. SolVES is available as a custom toolbar that must be installed in ArcMap. SolVES was designed on systems running Microsoft ${ }^{\circledR}$ Windows XP Professional Edition but should function with any operating system supported by ArcGIS 9.3. The time required to process each of the SolVES models will vary depending on factors including processor speed and the extent of the study area.

\section{Installation}

IMPORTANT NOTE: Installation requires the user to have administrative privileges on their local machine.

1. Download the SolVES.zip file from the SolVES website http://solves.cr.usgs.gov and place it in a temp directory on your machine.

2. Unzip the file to the temp directory.

3. Run the SolvesSetup.msi installation file by double clicking.

4. Click Next on the Welcome to the SolvesSetup Setup Wizard screen (fig. 2). 


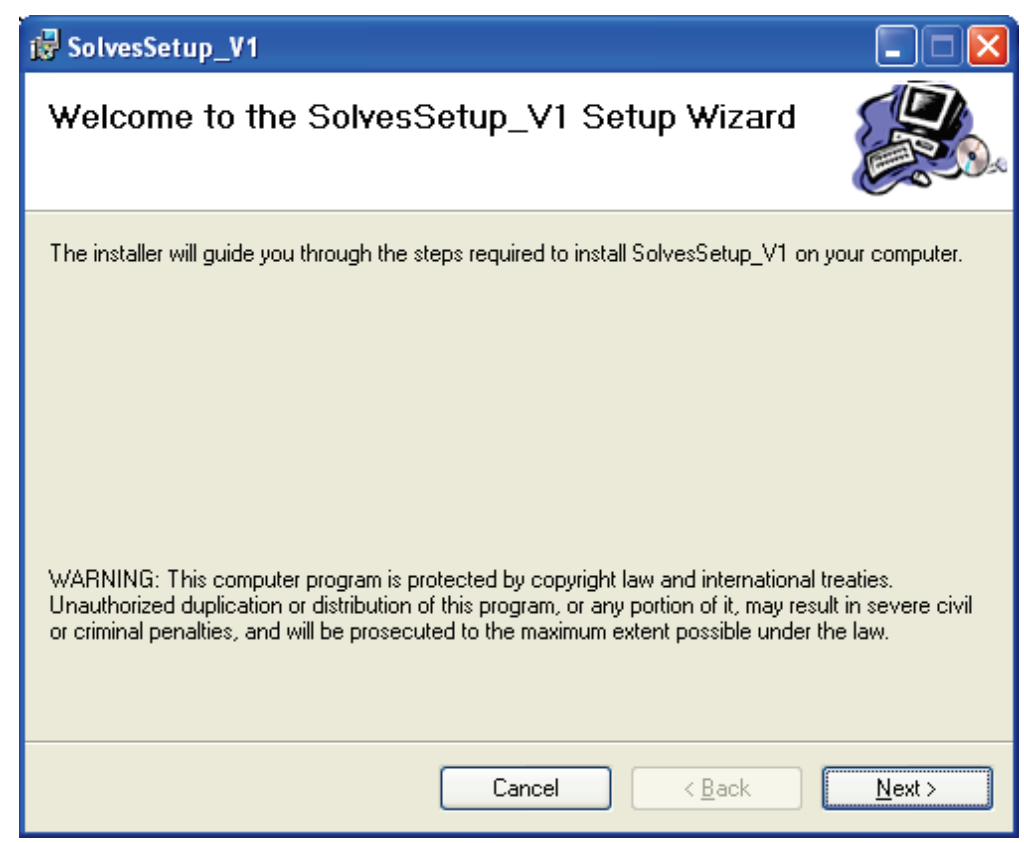

Figure 2. Welcome Setup Wizard screen.

5. On the Select Installation Folder screen, use the default folder or select a new one (fig. 3).

6. Select the radio button next to Everyone.

7. Click Next on the Select Installation Folder screen.

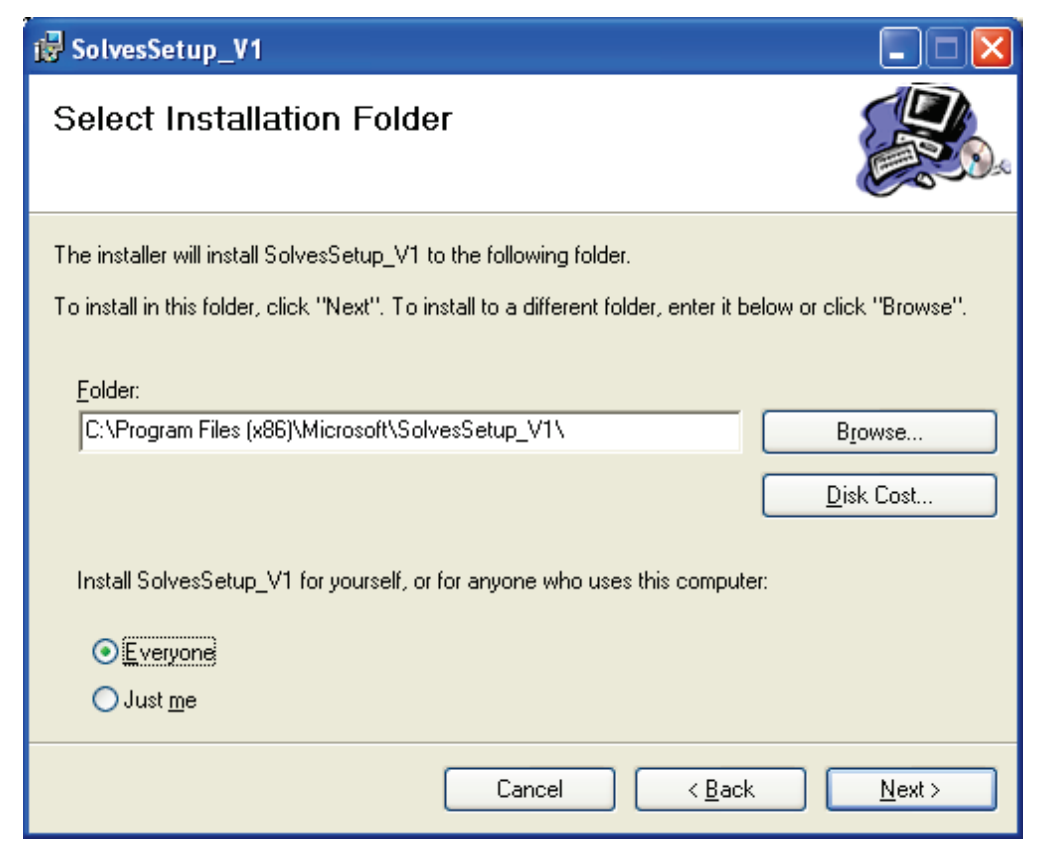

Figure 3. Select installation folder. 
8. Click Next on the Confirm Installation screen (fig. 4).

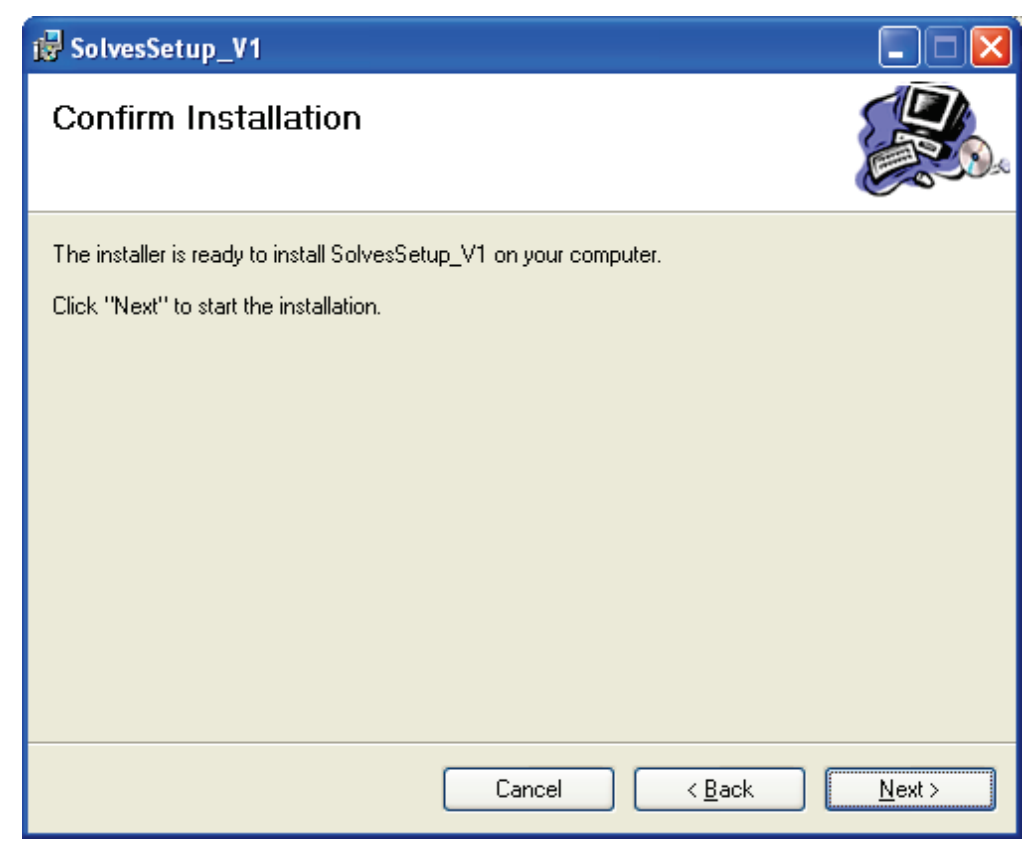

Figure 4. Confirm installation.

9. Wait while the tool is being installed (fig. 5).

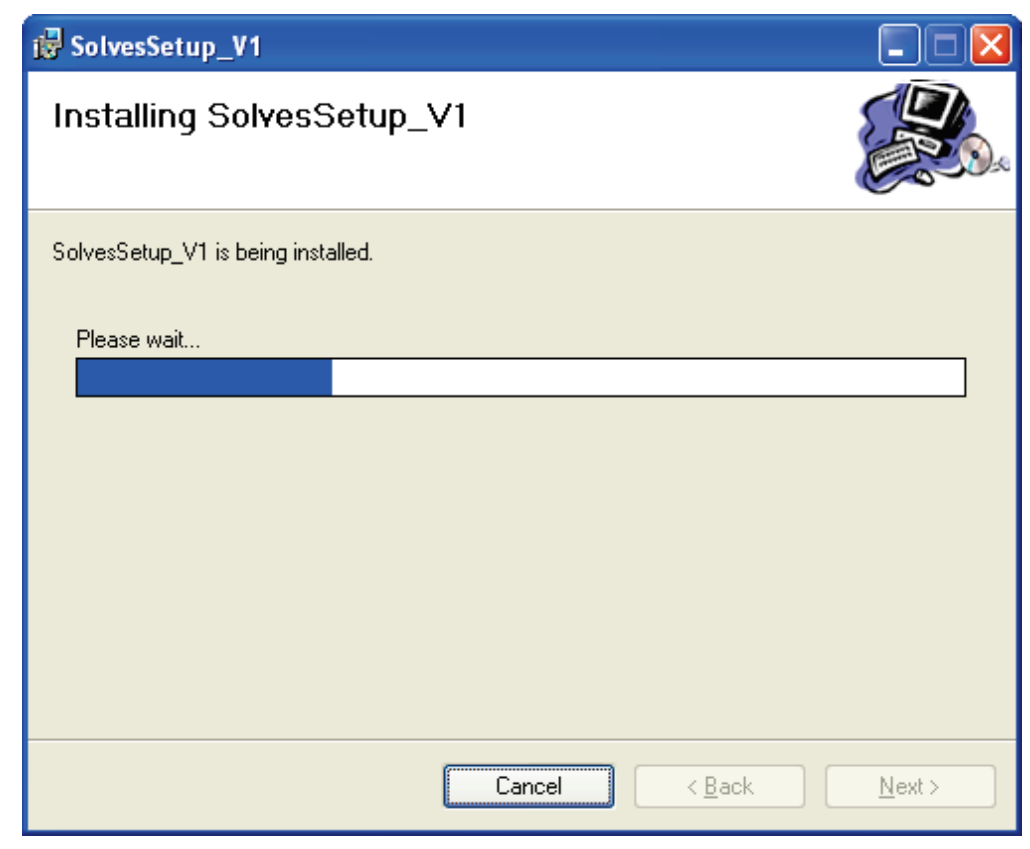

Figure 5. Installation in progress. 
10. Click Close on the Installation Complete screen after the tool has been installed (fig. 6).

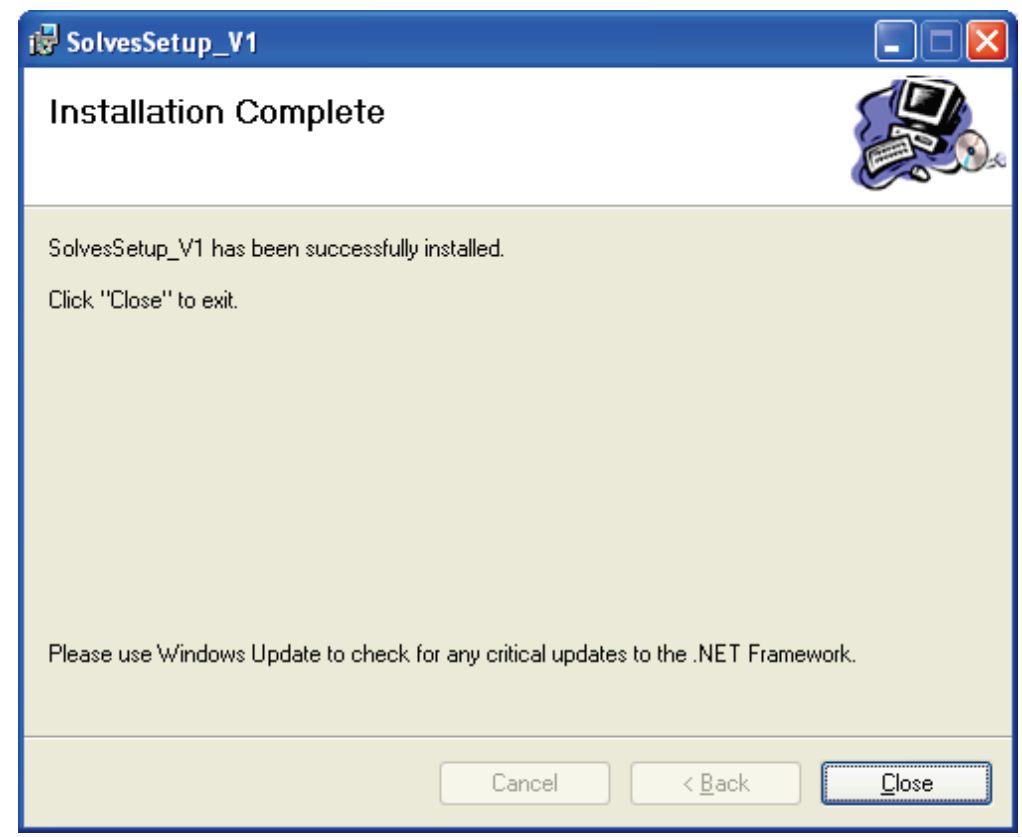

Figure 6. Installation complete. 


\section{Adding SolVES Toolbar to ArcMap}

1. Open ArcMap.

2. Choose Tools -> Extensions from menu.

3. Click on Spatial Analyst Extension (fig. 7).

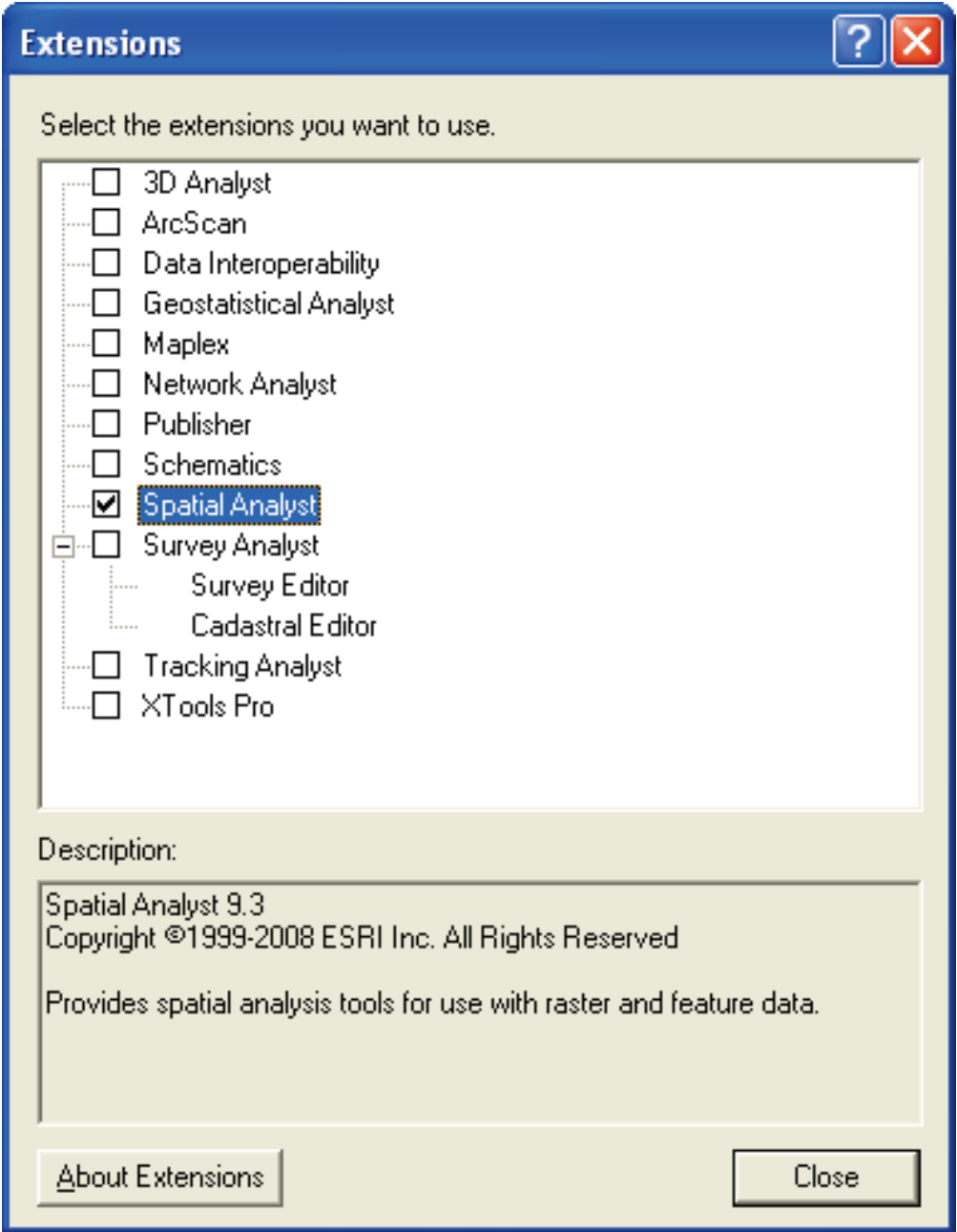

Figure 7. Extensions form.

4. Close the Extensions form.

5. Choose Tools -> Customize from menu.

6. Click on SolVES Toolbar (fig. 8). 


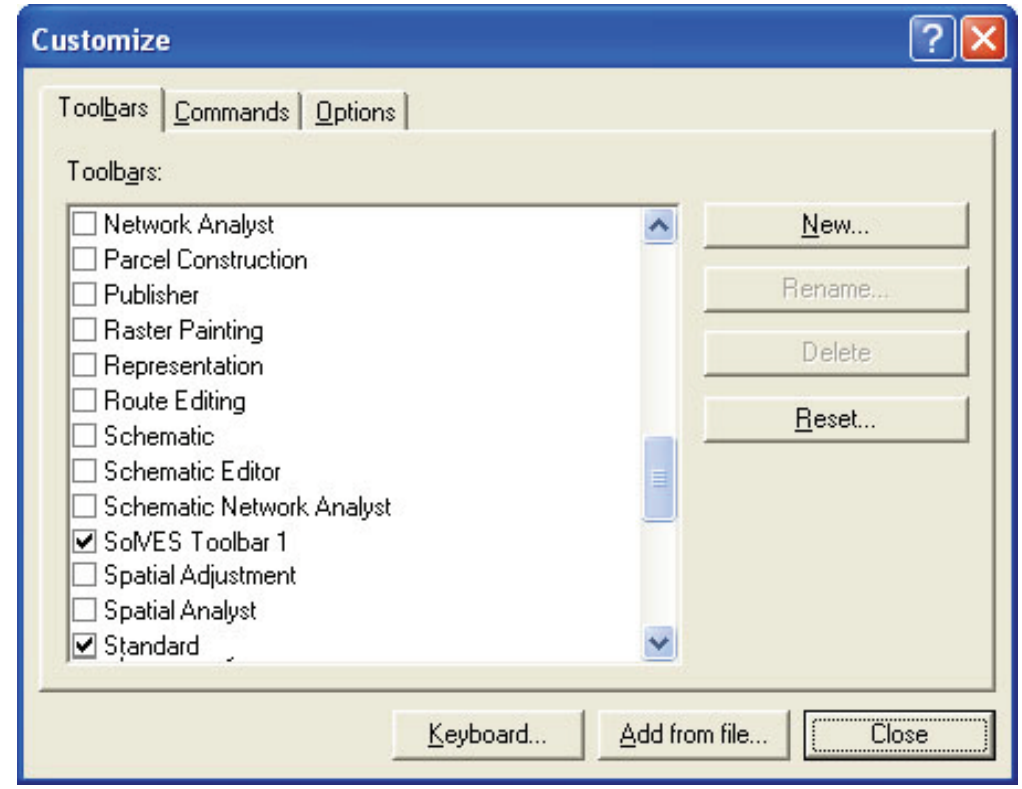

Figure 8. Customize form.

7. Close the Customize form.

8. The SolVES toolbar will be added to ArcMap.

9. Place the tool in the menu area of ArcMap (fig. 9).

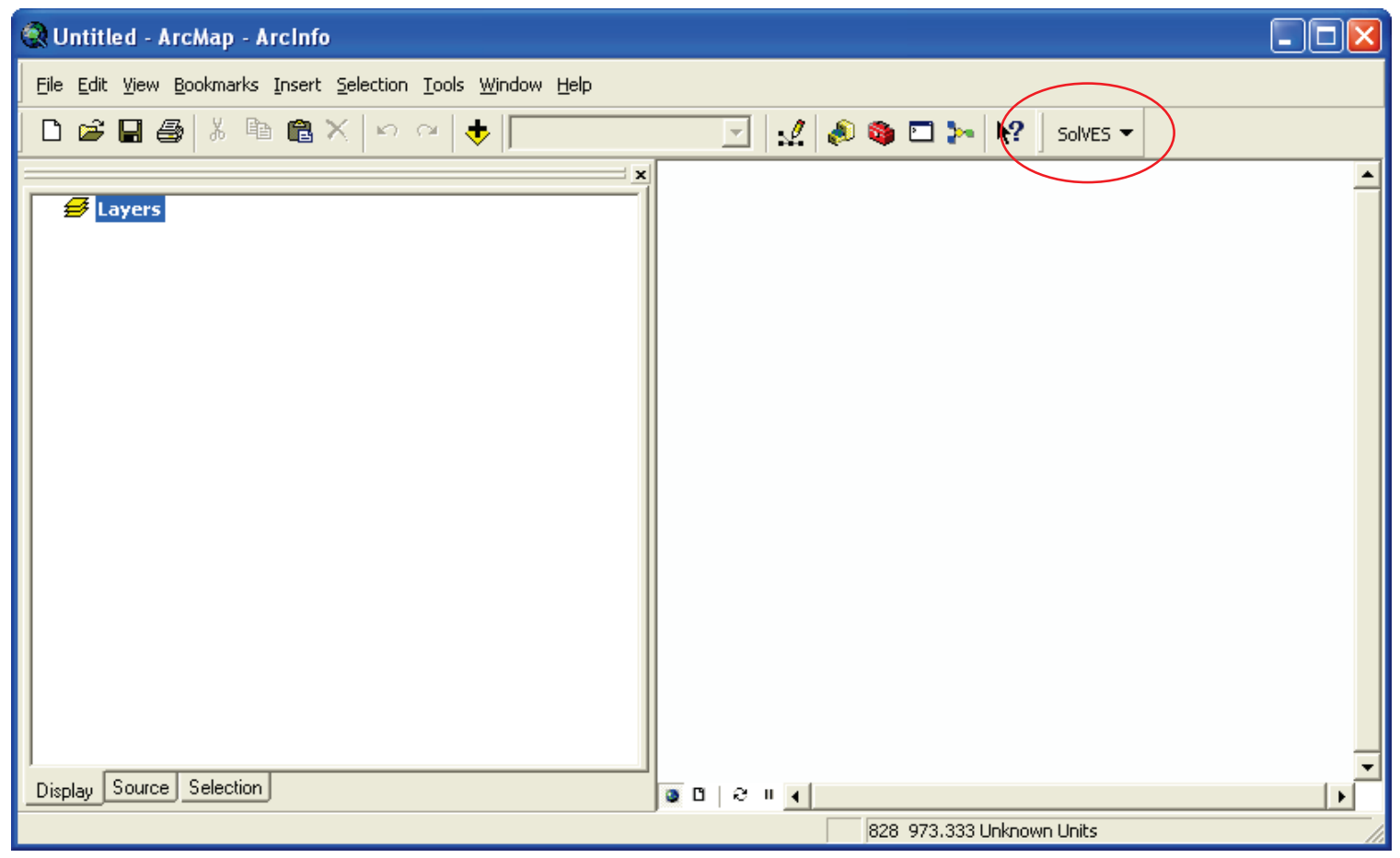

Figure 9. SolVES toolbar visible in ArcMap. 


\section{Data Installation}

1. Copy the Eco_Serv_Soc_Values folder to a directory on your machine.

2. If you have a correctly formatted file geodatabase to be used with the tool, load it into the Data folder contained within the Eco_Serv_Soc_Values folder copied to your machine to make it available to SolVES. (Please see the sections, Data Requirements and File Management including fig. 10, for information regarding formatting requirements and the SolVES directory structure.)

IMPORTANT NOTE: SolVES comes with two pre-loaded file geodatabases for demonstration purposes. One of these databases includes the survey data provided by CSU covering the Pike and San Isabel National Forests (PSI) along with landscape data for the area and is for use with the Ecosystem Services Social Values and Value Mapping Models. The other database includes landscape data covering Grand County, Colorado, and is for use with the Value Transfer Mapping Model. To use SolVES with the data from one of these file geodatabases, copy the file geodatabase from either the PSI or Grand_County folder to the Data folder to make the data accessible.

\section{Data Requirements}

SolVES uses various geospatial and tabular data that may be obtained in a variety of ArcGIS supported formats including coverages, shapefiles, grids, spreadsheet files, and so forth. For use with SolVES, these data must all be imported into a file geodatabase format. Instructions on how to import to the file geodatabases format can be found in the section, Source File Geodatabase Format. The remainder of this section describes the data required for the Ecosystem Services Social Values Model, the Value Mapping Model, and the Value Transfer Mapping Model.

\section{Landscape Data}

The required landscape data are necessary for the calculation of landscape metrics by the Value Mapping Model and the Value Transfer Mapping Model. Additionally, the Value Transfer Mapping Model uses some of these landscape data to generate predicted social value maps. All required landscape data must be at 30-m spatial resolution.

- Digital Elevation Model (DEM) - The DEM used for initial development of SolVES was downloaded from the Southwest Regional Gap Analysis Project (SWReGAP) website. http://fws-nmcfwru.nmsu.edu/swregap/habitatreview/model_attributes.htm Some alternative sites for obtaining a DEM include the following: http://seamless.usgs.gov/ http://datagateway.nrcs.usda.gov/

- Slope - A slope data layer (calculated as percent slope) can be derived from the DEM using the Slope surface analysis tool included in the ArcGIS Spatial Analyst extension.

- Distance to Roads (DTR) - DTR data, representing the Euclidian distance, in meters, to the nearest road (Watts and others, 2007) can be downloaded from The Road Indicator Project (TRIP) National Overview Road Metric Euclidian Distance (NORM ED) website: http://rmgsc.cr.usgs.gov/trip/data/

- Distance to Water (DTW) - DTW data are derivable from geodatabases downloaded from the National Hydrography Dataset (NHD) viewer website: 
http://nhdgeo.usgs.gov/viewer.htm

IMPORTANT NOTE: The Euclidian Distance tool, for calculating the shortest straight-line distance, included in the ArcGIS Spatial Analyst extension should be used to calculate the distance, in meters, from features representing lakes, ponds, rivers, streams, and springs. The NHD data provide the water features in separate point, line, and polygon feature classes requiring the distance to be calculated separately for each feature type. Once each of the distance grids have been calculated, the Spatial Analyst Cell Statistics tool should then be used to select the minimum distance value at each grid cell to produce the final DTW raster. This will result in a DTW grid indicating the distance of each cell to the nearest water feature.

- Landcover - The landcover data used for initial development of SolVES were downloaded from the SWReGAP website:

http://earth.gis.usu.edu/swgap/landcover.html

Some alternative sites for obtaining landcover data include the following:

http://seamless.usgs.gov/

http://datagateway.nrcs.usda.gov/

- Landform - The landform data used for initial development of SolVES were downloaded from the SWReGAP website:

http://fwsnmcfwru.nmsu.edu/swregap/habitatreview/model_attributes.htm

The landform data were previously categorized by SWReGAP based on DEM-derived slope and aspect data.

- Hillshade - A hillshade data layer can be derived from the DEM using the Spatial Analyst Hillshade surface analysis tool. It is used to provide a grayscale background for the social value map layouts generated by SolVES.

\section{Survey Data}

Specifically formatted attitude and preference survey response data are required in order to use SolVES' Ecosystem Services Social Values Model and Value Mapping Model. These data are not required, however, if only using the Value Transfer Mapping Model. The format of these data are based on survey results obtained by Clement and Cheng (2006) that, in turn, are based on collection procedures described by Brown and others (2002).

SolVES was initially developed based on a random mail survey of 2,000 households located within 45 miles of the PSI conducted in late 2004 and early 2005 (Clement and Cheng, 2006). The response rate was approximately 33 percent, with 684 surveys returned. The survey was divided into five sections. Section 1 requested information regarding each respondent's familiarity with the PSI such as when and how often they visited, if they derived any income from the PSI, and their interest level in what happens to the PSI in the next 10 to 15 years. Section 2 requested respondents to indicate whether they favored or opposed each of 18 public uses of the PSI such as logging for wood products, motorized recreation, and wilderness. Section 3 allowed respondents to indicate their views regarding various issues impacting the PSI such as the extent and purpose of road building and logging, reservoir development, and tradeoffs between recreational use and environmental quality. The first part of section 4 (4a) requested respondents to allocate or "spend" \$100 among 12 different social value types associated with the PSI. While dollar units were used for convenience to express value denominations (for example, points could have been used instead of dollars), it was explained in the survey instructions that this was not a reference to any actual money, either the respondents' or the Forest Service's. Once the allocation exercise was completed, respondents were then instructed in the second part of section 4 (4b) to hand-mark points (later digitized into a geographic data layer) on a series of maps of the PSI 
corresponding to the social value types to which they had allocated dollars. If the respondent had allocated dollars to Aesthetic value, for example, they were to place a mark or marks on the map at up to four locations indicating Aesthetic, and label and number each mark accordingly. Of the 684 surveys returned, the mapping section was completed for 55 percent of them. Finally, section 5 of the survey requested various demographic and socioeconomic information from each respondent.

For the current version of SolVES, the only required data are from survey sections $2,4 a$, and $4 b$, although future versions of SolVES may use data from the other survey sections. To use your own survey data with SolVES, the following minimal survey structural requirements must be met. Surveys designed to collect data containing the specific elements described below, even if not otherwise designed as the PSI survey, can be used with SolVES. Again, survey data are not required if only using the Value Transfer Mapping Model.

IMPORTANT NOTE: If you are using your own survey data, you must assign a unique identifier (Survey_ID), an integer value, to each returned survey in order to distinguish each survey and to relate its separate sections. See the section, Source File Geodatabase Format, for additional details regarding the location of the unique indentifier within the geodatabase schema.

- Public Uses (from survey section 2) - SolVES supports data collected regarding the following types of public uses (table 1) that include responses as to whether or not the public use is favored or opposed structured as an integer range from 1 to 5 (table 2). If your survey responses are structured to only include Favor or Oppose options, setting Favor values to 2 and Oppose values to 4 will make the responses compatible with SolVES, although the labeling of output will still include references to Strongly Favor and Strongly Oppose.

Table 1. Public uses supported by SolVES.

\begin{tabular}{l}
\hline \multicolumn{1}{c}{ Public Use } \\
\hline Commerical Mining \\
Commericial Outfitting and Guiding \\
Communication Sites and Utility Easements \\
Fish and Wildlife Habitat \\
Gathering Forest Products \\
Helicopter Skiing and Hiking \\
Logging for Fuels Reduction \\
Logging for Increased Water Collection \\
Logging for Wood Products \\
Motorized Recreation \\
Nonmotorized Recreation \\
Oil and Gas Drilling \\
Sightseeing \\
Sport Fishing \\
Sport Hunting \\
Wilderness \\
Wildlife Viewing and Observing \\
Other
\end{tabular}


Table 2. Attitude or preference integer values supported by SolVES.

\begin{tabular}{lc}
\hline Attitude or Preference & Integer Value \\
\hline Strongly Favor & 1 \\
Favor & 2 \\
No Opinion & 3 \\
Oppose & 4 \\
Strongly Oppose & 5 \\
\hline
\end{tabular}

- Value Allocation (from survey section 4a) - SolVES supports integer values ranging from 0 to 100 allocated to any of the following 12 social value types as described in the survey (table 3 ).

Table 3. Description of social value types supported by SoIVES.

\begin{tabular}{|c|c|}
\hline Social Value Type & Description \\
\hline Aesthetic & I value these forests because I enjoy the scenery, sights, sounds, smells, etc. \\
\hline Biodiversity & I value these forests because they provide a variety of fish, wildlife, plant life, etc. \\
\hline Cultural & $\begin{array}{l}\text { I value these forests because they are a place for me to continue and pass down the } \\
\text { wisdom and knowledge, traditions, and way of life of my ancestors. }\end{array}$ \\
\hline Economic & $\begin{array}{l}\text { I value these forests because they provide timber, fisheries, minerals, and/or tourism } \\
\text { opportunities such as outfitting and guiding. }\end{array}$ \\
\hline Future & $\begin{array}{l}\text { I value these forests because they allow future generations to know and experience the } \\
\text { forests as they are now. }\end{array}$ \\
\hline Historic & $\begin{array}{l}\text { I value these forests because they have places and things of natural and human history that } \\
\text { matter to me, others, or the nation. }\end{array}$ \\
\hline Intrinsic & I value these forests in and of themselves, whether people are present or not. \\
\hline Learning & $\begin{array}{l}\text { I value these forests because we can learn about the environment through scientific } \\
\text { observation or experimentation. }\end{array}$ \\
\hline Life Sustaining & $\begin{array}{l}\text { I value these forests because they help produce, preserve, clean, and renew air, soil, and } \\
\text { water. }\end{array}$ \\
\hline Recreation & $\begin{array}{l}\text { I value these forests because they provide a place for my favorite outdoor recreation } \\
\text { activities. }\end{array}$ \\
\hline Spiritual & $\begin{array}{l}\text { I value these forests because they are a sacred, religious, or spiritually special place to me } \\
\text { or because I feel reverence and respect for nature there. }\end{array}$ \\
\hline Therapeutic & I value these forests because they make me feel better, physically and/or mentally. \\
\hline
\end{tabular}

- Social Value Point Mapping (from survey section 4b) - SolVES supports point layers representing the digitized points that survey respondents marked on a map or maps of a study area. Each point must also be identified by a survey respondent as representing one of the 12 social value types described above. 


\section{Other Spatial Data}

SolVES also requires the following geospatial data layers (table 4).

Table 4. Other SoIVES spatial data requirements.

\begin{tabular}{lll}
\hline \multicolumn{1}{c}{ Layer Name } & Feature Type & \multicolumn{1}{c}{ Field Description } \\
\hline Study_Area & Polygon & Defines study area boundary. \\
Extent & Polygon & Defines rectangular extent of study area. \\
State & Polygon & Defines State or States where study area is located. \\
Counties & Polygon & $\begin{array}{l}\text { An alternative layer to States to define county or counties where study area is located. } \\
\end{array}$ \\
& & (Any other polygon feature layer type appropriate for orienting the study area on the \\
& & locator map may be used.) \\
\hline
\end{tabular}

\section{File Management}

\section{Directory Structure}

SolVES uses the directory structure illustrated below (fig. 10).

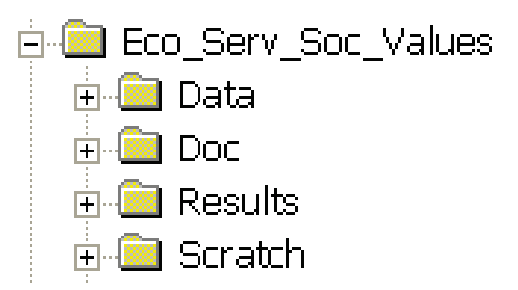

Figure 10. SolVES directory structure.

Eco_Serv_Soc_Values is the root directory and contains the elements described below (table 5):

Table 5. Description of the SolVES directory structure.

\begin{tabular}{ll}
\hline \multicolumn{1}{c}{ Folder Name } & \multicolumn{1}{c}{ Folder Description } \\
\hline Data & This folder holds the required source file geodatabase \\
& "Eco_Soc_Values.gdb" necessary for SolVES to function. All \\
& landscape and survey data will be imported into this database. This \\
& folder also contains graph templates for landscape metrics and a layer \\
& defining the Value Index map color scheme. Folders named PSI and \\
& Grand_County are located inside the Data folder and contain the \\
& sample file geodatabases included with SolVES. For SolVES to work \\
& with either of these sample file geodatabases, one must first be \\
& copied to the Data folder. \\
& SolVES supporting documentation, including a copy of this user \\
manual, are stored here. & \\
Doc & All final data SolVES generates are saved here to a file geodatabase. \\
Results & All intermediate results that are generated by SolVES are written to \\
Scratch & this folder. Most intermediate data are temporarily stored in a file \\
& geodatabases "Scratch.gdb" although some other temporary files are \\
& written to the folder. \\
\hline
\end{tabular}




\section{Source File Geodatabase Format}

A diagram of the Eco_Soc_Values.gdb source file geodatabase is shown below (fig. 11). Most, but not all, of the data elements shown are currently required for SolVES to function. Each element is described below including whether or not it is currently required and the specific formatting necessary for each of the required data elements.

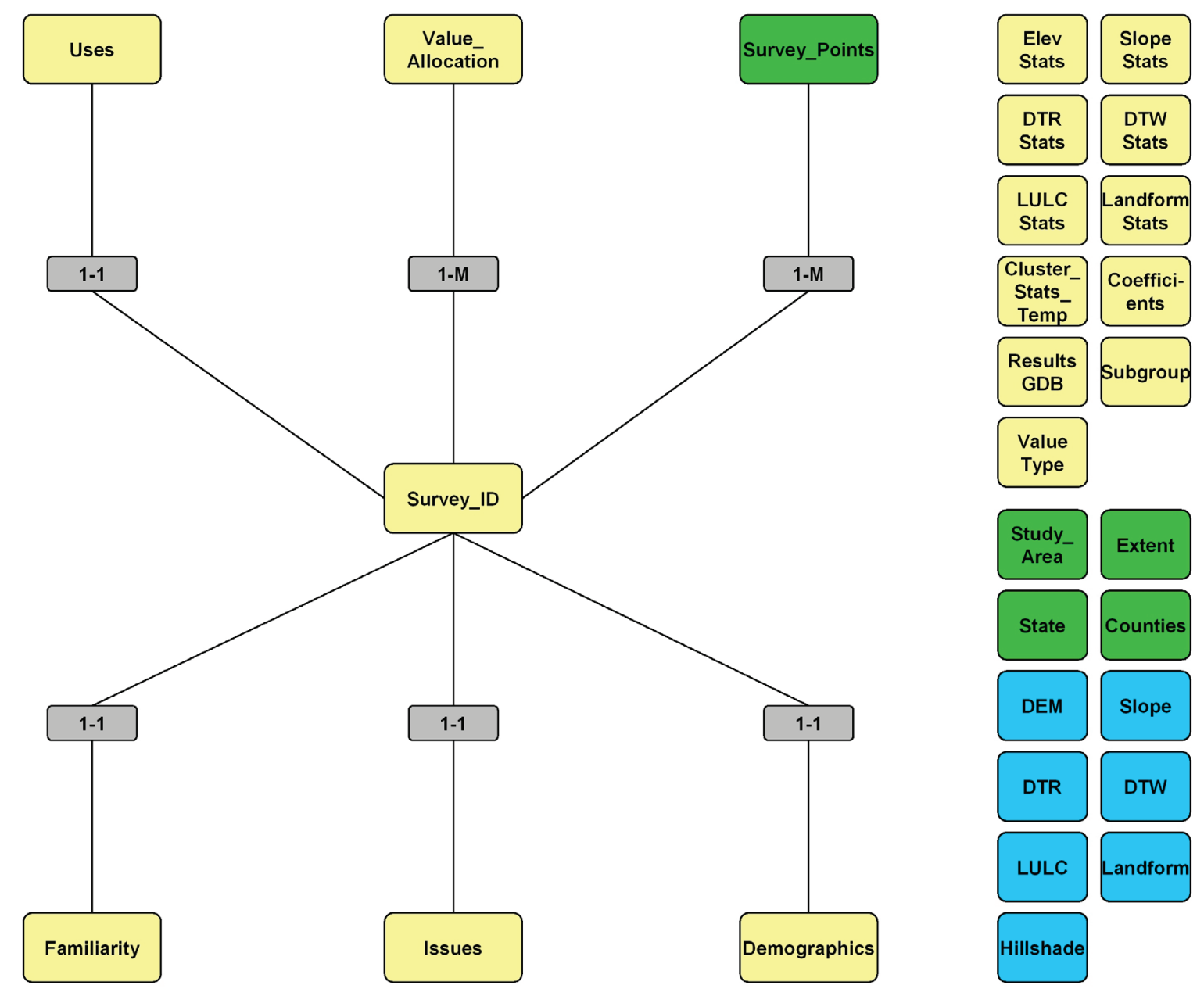

Figure 11. Overview of the Eco_Soc_Values.gdb source file geodatabase.

IMPORTANT NOTE: The sample file geodatabase data layers included with SolVES were all projected from their native projections to a common Albers Equal Area NAD 83 projection for inclusion in the source file geodatabases. While you may use any projection suitable to your own geospatial data, it is CRUCIAL that all of these data share a common projection before completing any geospatial assessments using SolVES. 
- Landscape Data (Blue, fig. 11): These are all required data having a 30-m spatial resolution raster format. The required raster names, field names, field data types, and descriptions are listed below (table 6).

Table 6. Formatting requirements for landscape rasters.

\begin{tabular}{llll}
\hline \multicolumn{1}{c}{ Raster Name } & \multicolumn{1}{c}{ Field Names } & \multicolumn{1}{c}{ Field Data Type } & \multicolumn{1}{c}{ Field Description } \\
\hline DEM & VALUE & Long Integer & Elevation in meters. \\
Slope & VALUE & Long Integer & Percent slope. \\
DTR & VALUE & Long Integer & Distance to roads in meters. \\
DTW & VALUE & Long Integer & Distance to water in meters. \\
LULC & VALUE & Long Integer & Unique landcover category. \\
& DESCRIPTIO & String & $\begin{array}{l}\text { Textual description of landcover } \\
\text { category. }\end{array}$ \\
& (note there is no "N" at & & \\
& the end of the field & & Unique landform category. \\
Landform & name) & Toxtual description of landform \\
& VALUE & String & category. \\
& LANDFORM & & Grayscale value. \\
\hline
\end{tabular}

- Tables (Yellow, fig. 11): These include data from each of the nonspatial survey sections as well as the tables where landscape metrics calculated by SolVES are written. Table requirements are listed below (tables 7-9). 
Table 7. Formatting requirements for tables.

\begin{tabular}{|c|c|c|c|}
\hline Table Name & Field Names & $\begin{array}{l}\text { Field Data } \\
\text { Type }\end{array}$ & Field Description \\
\hline Survey_ID & SURVEY_ID & Long Integer & Primary key for relating separate survey sections. \\
\hline \multirow[t]{20}{*}{ Uses } & SURVEY_ID & Long Integer & Primary key for relating separate survey sections. \\
\hline & MINING & Long Integer & $\begin{array}{l}\text { Commercial Mining: Attitude or preference survey section } 2 \text { response } \\
\text { ranging from } 1 \text { to } 5 \text { (see table 2). }\end{array}$ \\
\hline & OUTFITTING & Long Integer & $\begin{array}{l}\text { Commercial Outfitting and Guiding: attitude or preference survey } \\
\text { section } 2 \text { response ranging from } 1 \text { to } 5 \text { (see table } 2 \text { ). }\end{array}$ \\
\hline & COMM_UTILITY & Long Integer & $\begin{array}{l}\text { Communication Sites and Utility Easements: attitude or preference } \\
\text { survey section } 2 \text { response ranging from } 1 \text { to } 5 \text { (see table } 2 \text { ). }\end{array}$ \\
\hline & HABITAT & Long Integer & $\begin{array}{l}\text { Fish and Wildlife Habitat: attitude or preference survey section } 2 \\
\text { response ranging from } 1 \text { to } 5 \text { (see table } 2 \text { ). }\end{array}$ \\
\hline & GATHERING & Long Integer & $\begin{array}{l}\text { Gathering Forest Products: attitude or preference survey section } 2 \\
\text { response ranging from } 1 \text { to } 5 \text { (see table } 2 \text { ). }\end{array}$ \\
\hline & HELI_SKI_HIKE & Long Integer & $\begin{array}{l}\text { Helicopter Skiing and Hiking: attitude or preference survey section } 2 \\
\text { response ranging from } 1 \text { to } 5 \text { (see table } 2 \text { ). }\end{array}$ \\
\hline & LOG_FUEL_RED & Long Integer & $\begin{array}{l}\text { Logging for Fuels Reduction: attitude or preference survey section } 2 \\
\text { response ranging from } 1 \text { to } 5 \text { (see table } 2 \text { ). }\end{array}$ \\
\hline & LOG_WATER & Long Integer & $\begin{array}{l}\text { Logging for Increased Water Collection: attitude or preference survey } \\
\text { section } 2 \text { response ranging from } 1 \text { to } 5 \text { (see table } 2 \text { ). }\end{array}$ \\
\hline & LOG_WOOD & Long Integer & $\begin{array}{l}\text { Logging for Wood Products: attitude or preference survey section } 2 \\
\text { response ranging from } 1 \text { to } 5 \text { (see table } 2 \text { ). }\end{array}$ \\
\hline & MOTOR & Long Integer & $\begin{array}{l}\text { Motorized Recreation: attitude or preference survey section } 2 \text { response } \\
\text { ranging from } 1 \text { to } 5 \text { (see table 2). }\end{array}$ \\
\hline & NON_MOTOR & Long Integer & $\begin{array}{l}\text { Nonmotorized Recreation: attitude or preference survey section } 2 \\
\text { response ranging from } 1 \text { to } 5 \text { (see table } 2 \text { ). }\end{array}$ \\
\hline & OIL_GAS & Long Integer & $\begin{array}{l}\text { Oil and Gas Drilling: attitude or preference survey section } 2 \text { response } \\
\text { ranging from } 1 \text { to } 5 \text { (see table 2). }\end{array}$ \\
\hline & SIGHT_SEE & Long Integer & $\begin{array}{l}\text { Sightseeing: attitude or preference survey section } 2 \text { response ranging } \\
\text { from } 1 \text { to } 5 \text { (see table } 2 \text { ). }\end{array}$ \\
\hline & SPORT_FISH & Long Integer & $\begin{array}{l}\text { Sport Fishing: attitude or preference survey section } 2 \text { response ranging } \\
\text { from } 1 \text { to } 5 \text { (see table } 2 \text { ). }\end{array}$ \\
\hline & SPORT_HUNT & Long Integer & $\begin{array}{l}\text { Sport Hunting: attitude or preference survey section } 2 \text { response } \\
\text { ranging from } 1 \text { to } 5 \text { (see table } 2 \text { ). }\end{array}$ \\
\hline & WILDERNESS & Long Integer & $\begin{array}{l}\text { Wilderness: attitude or preference survey section } 2 \text { response ranging } \\
\text { from } 1 \text { to } 5 \text { (see table } 2 \text { ). }\end{array}$ \\
\hline & WILDLIFE_VIEW & Long Integer & $\begin{array}{l}\text { Wildlife Viewing and Observing: attitude or preference survey section } \\
2 \text { response ranging from } 1 \text { to } 5 \text { (see table } 2 \text { ). }\end{array}$ \\
\hline & OTHER & Long Integer & $\begin{array}{l}\text { Other: attitude or preference survey section } 2 \text { response ranging from } 1 \\
\text { to } 5 \text { (see table } 2 \text { ). }\end{array}$ \\
\hline & OTHER_NOTES & String & Optional field to store any notes regarding "Other" uses. \\
\hline \multirow[t]{3}{*}{ Value_Allocation } & SURVEY_ID & Long Integer & Primary key for relating separate survey sections. \\
\hline & AMOUNT & Long Integer & Value allocation survey section $4 \mathrm{a}$ response ranging from 0 to 100. \\
\hline & VALUE_TYPE & Long Integer & $\begin{array}{l}\text { Unique identifer of social value type to which allocation was made } \\
\text { (see table 8). }\end{array}$ \\
\hline
\end{tabular}


Table 8. Integer values for populating VALUE_TYPE field.

\begin{tabular}{lc}
\hline Social Value Type & VALUE_TYPE \\
\hline Aesthetic & 1 \\
Biodiversity & 2 \\
Cultural & 3 \\
Economic & 4 \\
Future & 5 \\
Historic & 6 \\
Intrinsic & 7 \\
Learning & 8 \\
Life Sustaining & 9 \\
Recreation & 10 \\
Spiritual & 11 \\
Therapeutic & 12 \\
\hline
\end{tabular}

Table 9. Tables not requiring user preparation or interaction.

\begin{tabular}{ll}
\hline \multicolumn{1}{c}{ Table Name } & \multicolumn{1}{c}{ Table Description } \\
\hline ElevStats & Elevation statistics are written to this table. \\
SlopeStats & Slope statistics are written to this table. \\
DTRStats & DTR statistics are written to this table. \\
DTWStats & DTW statistics are written to this table. \\
LULCStats & Landcover statistics are written to this table. \\
LandformStats & Landform statistics are written to this table. \\
Cluster_Stats_Temp & $\begin{array}{l}\text { This is a template table used to generate a table of nearest neighbor statistics measuring } \\
\text { the relative clustering or dispersion of selected mapped points from survey section 4b. }\end{array}$ \\
Coefficients & Regression coefficients generated from the multiple regression of landscape metrics that \\
& were significantly correlated with the Value Index in the PSI study area (see fig. 12). \\
ResultsGBD & Optional user updates are described in the section, Advanced Options (see table 11). \\
& User-entered public use and attitude or preference parameters used for naming the results \\
Subgroup & file geodatabase. \\
ValueType & User-entered public use and attitude or preference parameters used for labeling social \\
Familiarity & value map layouts. \\
Issues & User-entered value type parameters used for labeling social value map layouts. \\
Demographics & Not currently used by SolVES. \\
\hline
\end{tabular}




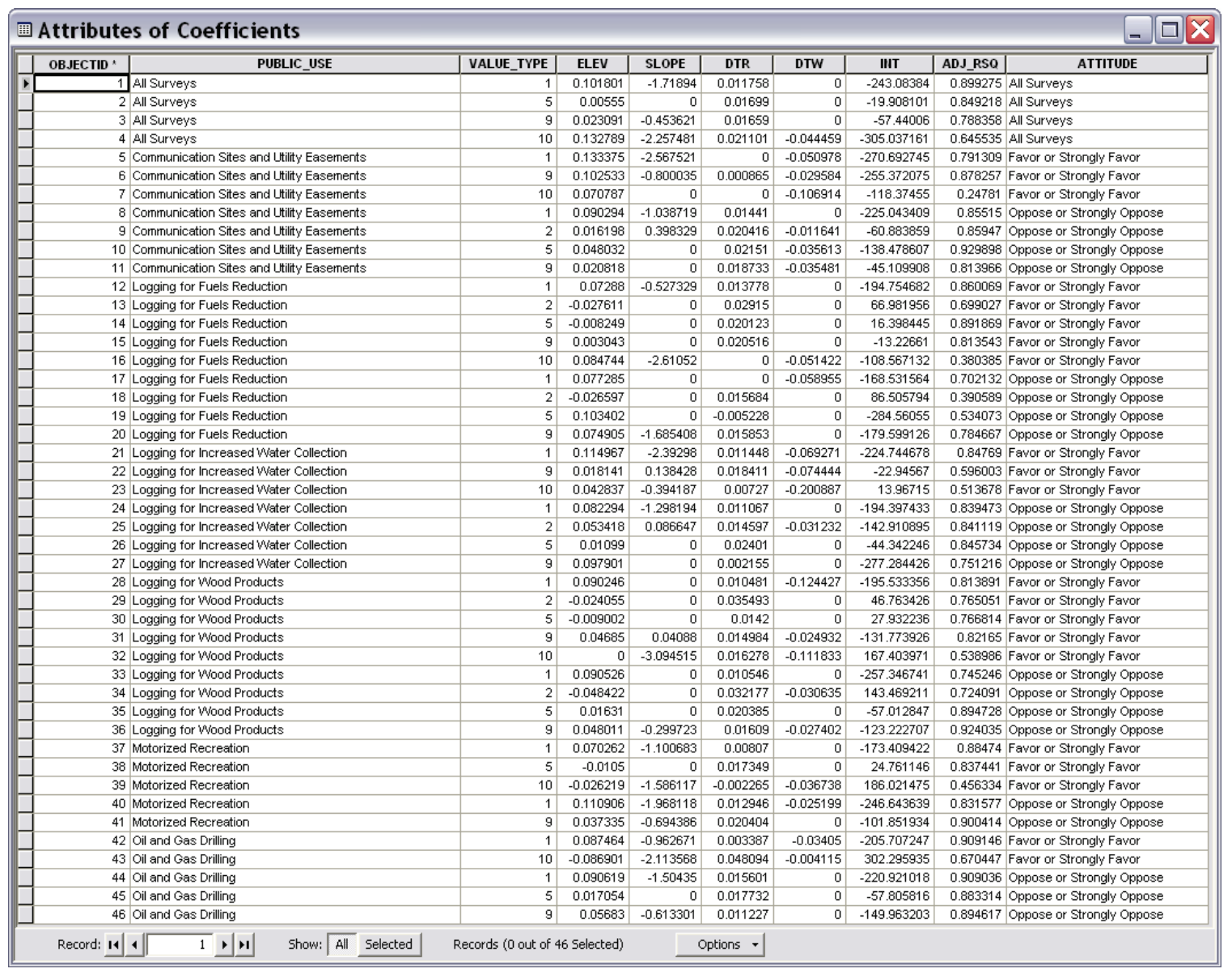

Figure 12. Coefficients table. 
- Feature Class Data (Green, fig. 11): These include the mapped points from section $4 \mathrm{~b}$ of the survey as well as various other boundary polygon layers as listed below (table 10).

Table 10. Formatting requirements for feature classes.

\begin{tabular}{|c|c|c|c|}
\hline Feature Class Name & Field Names & Field Data Type & Field Description \\
\hline \multirow[t]{3}{*}{ Survey_Points } & SURVEY ID & Long Integer & Primary key for relating separate survey sections. \\
\hline & VALUE_TYPE & Long Integer & $\begin{array}{l}\text { Unique identifer of social value type to which } \\
\text { allocation was made (see table } 8 \text { ). }\end{array}$ \\
\hline & PLACE_NAME & String & Optional field for labeling or describing each point. \\
\hline Study_Area & - & - & $\begin{array}{l}\text { This is a required polygon feature class representing } \\
\text { the study area boundary. It is used by SolVES as a } \\
\text { mask for spatial analysis as well as for display } \\
\text { purposes. While it must be named "Study_Area," } \\
\text { there are no specific field requirements. }\end{array}$ \\
\hline Extent & VALUE & Short Integer & $\begin{array}{l}\text { This is a required polygon feature class representing } \\
\text { the rectangular extent of the study area. It is used by } \\
\text { SolVES to prevent boundary effects that negatively } \\
\text { impact the cartographic quality of the social value } \\
\text { maps produced by the Ecosystem Services Social } \\
\text { Values and Value Mapping Models. }\end{array}$ \\
\hline State (or Counties) & - & - & $\begin{array}{l}\text { This is a required polygon feature class representing } \\
\text { the State or States containing the study area. It is } \\
\text { used by SolVES for display purposes. While it must } \\
\text { be named "State," there are no specific field } \\
\text { requirements. (Alternatively, a "Counties" feature } \\
\text { layer or other polygon feature layer appropriate for } \\
\text { orienting the study area on a locator map included in } \\
\text { the SolVES map output may be used.) }\end{array}$ \\
\hline
\end{tabular}

- Relation Classes (Gray, fig. 11): These define the relation between the various survey sections using the unique identifier "SURVEY_ID" as the primary key. As currently defined by the survey design, each survey may include only one set of responses in the Familiarity, Uses, Issues, and Demographics tables (1-1), but multiple responses may be included in the Value Allocation table and the Survey_Points feature class (1-M).

\section{Importing and Loading Data to the Source File Geodatabase}

As previously discussed, the landscape and survey data used by SolVES comes from numerous sources in a variety of formats. Since SolVES was designed to work in conjunction with a file geodatabase, when supplying your own data, it must be imported or loaded into Eco_Soc_Values.gdb. Prior to this process, please review the section, Source File Geodatabase Format, to determine how to properly prepare and format the data you are supplying. Once completed, access ArcCatalog and navigate to Eco_Soc_Values.gdb as shown below (fig. 13). Then complete the following sequence of instructions. 


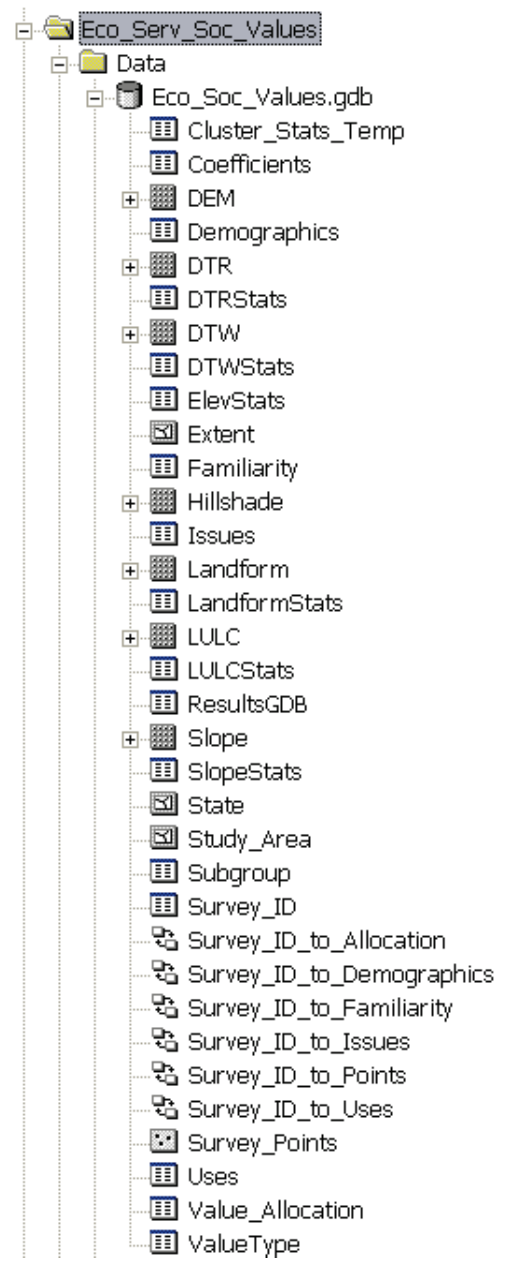

Figure 13. Eco_Soc_Values.gdb as seen in ArcCatalog.

1. If you will be supplying your own data, you will need to delete some of the existing data from Eco_Soc_Values.gdb. You may wish to begin by backing up the supplied geodatabase by copying it to some other location.

2. Delete (by right clicking on each and selecting Delete) the following raster data:

- DEM

- DTR

- DTW

- Hillshade

- Landform

- LULC

- Slope

3. Delete the following feature classes:

- Extent

- Study_Area

4. Delete the CONTENTS of the following feature class and tables NOT the feature class and tables themselves. You do not want to delete them as it will remove the relation defined between 
them and the Survey_ID table. This deletion can be accomplished through ArcCatalog by using the Delete Rows tool located in the Table toolset under Data Management Tools and navigating to the table or feature class as shown below (fig. 14). (This step may be skipped if you will only be using the Value Transfer Mapping Model in your study area.)

- Survey_Points

- Uses

- Value_Allocation

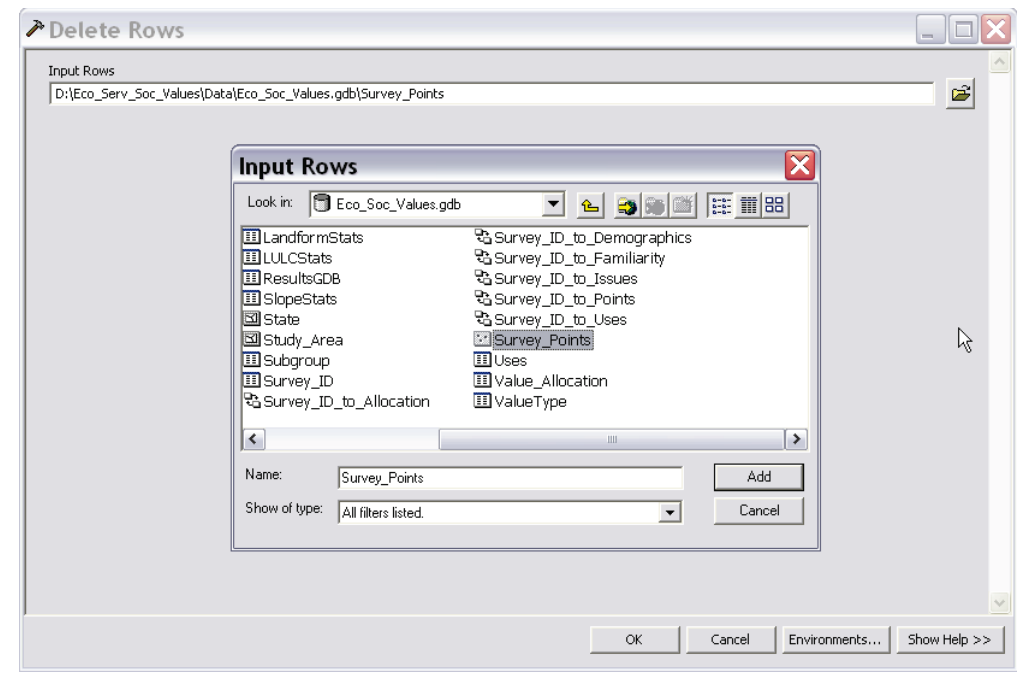

Figure 14. Using the Delete Rows tool.

5. Import each of your rasters replacing those deleted in step 2 into Eco_Soc_Values.gdb by right clicking on Eco_Soc_Values.gdb, selecting import, and then selecting Raster Datasets as shown below (fig. 15). You can then navigate to where your prepared rasters are stored, select them all and complete the import in a single process.

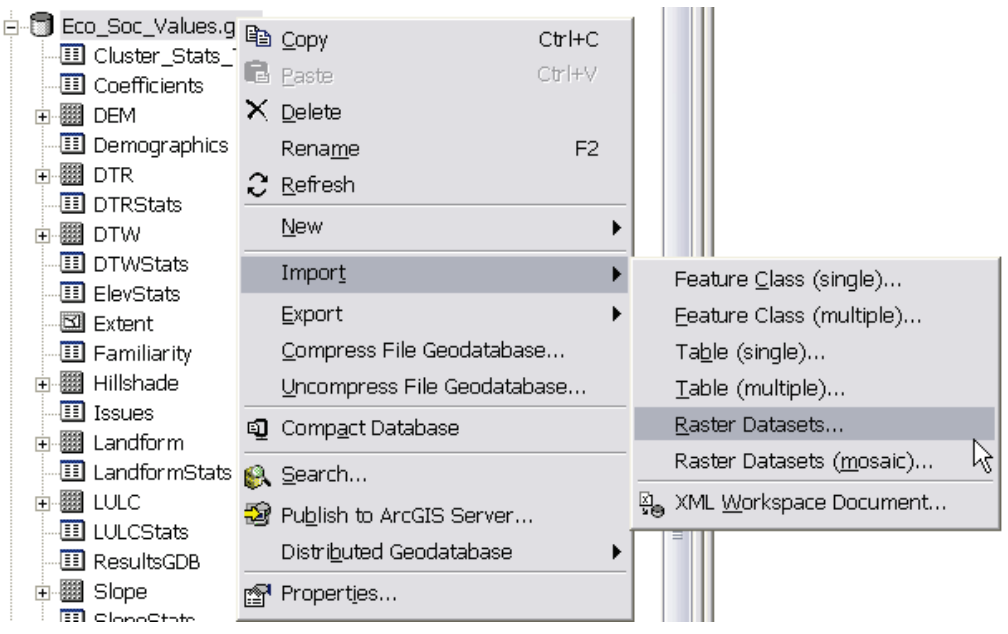

Figure 15. Importing rasters in ArcCatalog. 
6. Import each of your feature classes replacing those deleted in step 3 by right clicking on Eco_Soc_Values.gdb, selecting import, and then selecting Feature Class (multiple). You can then navigate to where your prepared feature classes are stored, select them all, and complete the import in a single process.

7. Load your records that will replace the previous contents of the Survey_Points feature class and the Uses and Value_Allocation tables by right clicking on each, selecting Load, selecting Load Data, and following the Simple Data Loader Wizard instructions as shown below (fig. 16). You will need to repeat this process separately for the feature class and each of the tables. Once loading is completed, you can run SolVES using your own data.

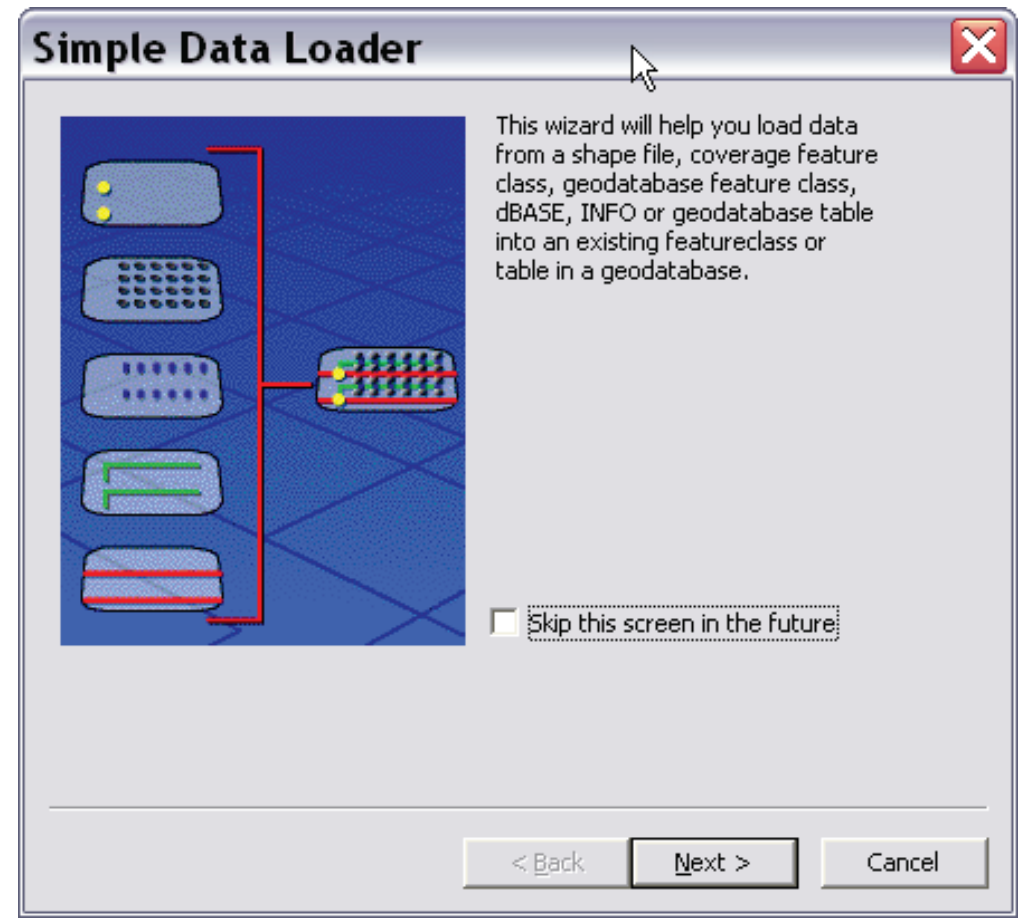

Figure 16. Simple Data Loader Wizard.

\section{Intermediate and Final Output}

Intermediate data are written to a file geodatabase named Scratch.gdb located in the Scratch folder under the root directory. Each time SolVES is run, Scratch.gdb is overwritten.

Final output are written to a file geodatabase located in the Results folder under the root directory. Each time SolVES is run, a separate file geodatabase is generated with a name derived from the user-entered parameters from either the Ecosystem Services Social Values Model or the Value Transfer Mapping Model.

Results geodatabases generated by the Ecosystem Services Social Values Model use the naming convention of the Uses table field name (see table 7) for the selected public use followed by either "FAVOR" or "OPPOSE." For example, if the user-selected public use parameter is Motorized Recreation and the attitude or preference parameter is Oppose or Strongly Oppose, then the results geodatabases will have the name: "MOTOR_OPPOSE.gdb." Each social value map raster subsequently 
generated by the Value Mapping Model will be named according to the user-selected social value type parameter. For example, the Aesthetic social value map raster will be named "Aesthetic."

The Value Transfer Mapping Model generates a separate geodatabase for each public use, attitude or preference, and social value type rather than storing all social value maps in a single file geodatabase. The naming convention used by the Value Transfer Mapping Model begins the same as that for the Ecosystem Services Social Values Mapping Model, but the name is appended with "VT[\#]" with VT standing for value transfer and the [\#] being an integer value from 1 to 12 corresponding to the user-selected social value type (see table 8). Using the same parameters from the previous paragraph, the geodatabase would then have the name: "MOTOR_OPPOSE_VT1.gdb".

The contents of a results geodatabase generated by the Ecosystem Services Social Values Model using the example parameters from above are shown below (fig. 17). It contains not only the Value Index raster for the selected social value type (Aesthetic), but also the landscape metrics for the selected social value type (for example, AestheticDTRStats), and all of the points (PointsSelect) and value allocations (ValueAllocationSelect) associated with the survey group opposed or strongly opposed to motorized recreation. You will also notice a second Value Index raster and set of landscape metrics that include " 100 " in their names. These data represent an additional calculation of the Value Index and associated metrics on a 100-point rather than a 10-point scale. The purpose of these 100-point datasets is to provide a larger number of data points for statistical analyses of the relation between the Value Index and the landscape metrics.

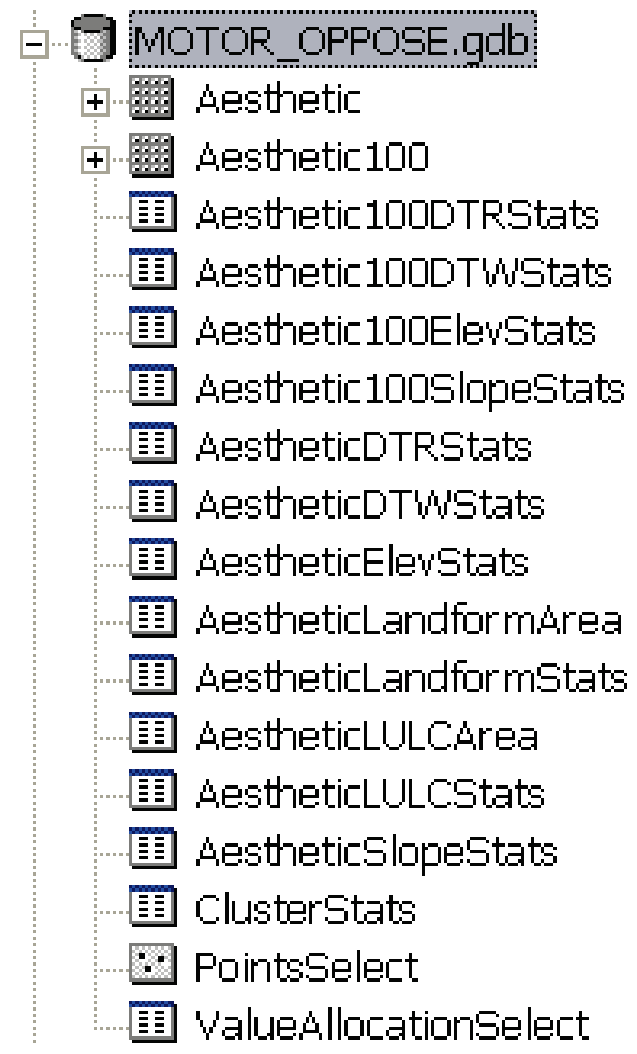

Figure 17. Sample contents of a results geodatabase. 


\section{Project Setup}

1. To begin using SolVES, a new project will need to be started by selecting Project Setup and New SolVES Project from the toolbar as shown below (fig. 18).

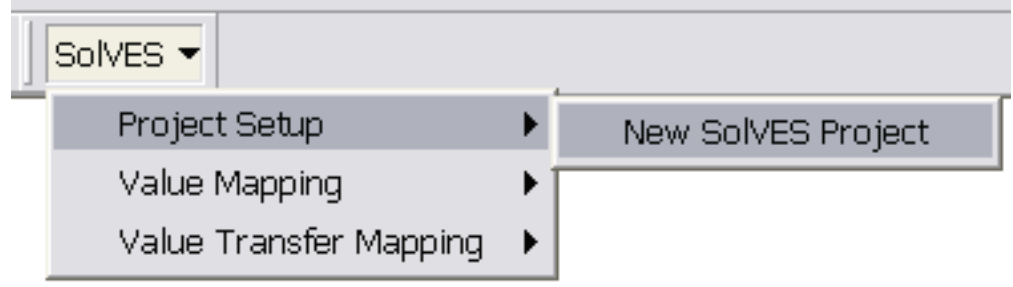

Figure 18. Starting a new SolVES project.

2. Once the Project Setup form is opened, navigate to wherever the Eco_Serv_Soc_Values root directory is located to set the Home Directory (fig. 19).

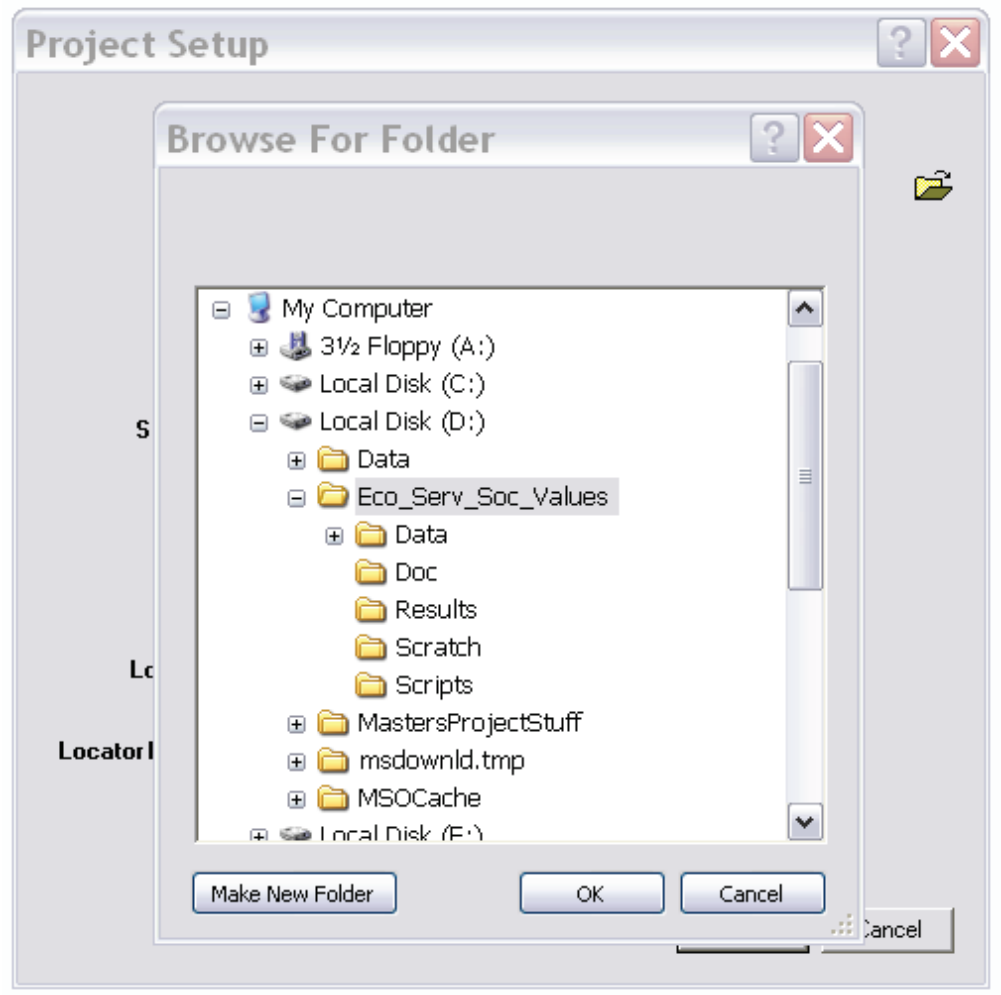

Figure 19. Navigating to the Home Directory from the Project Setup form.

3. Enter a Forest Name for your study area (fig. 20).

4. By default, SolVES locates the Study_Area polygon in the source file geodatabase.

5. Enter a Study Area Name. This may be the same as the Forest Name.

6. By default, SolVES locates the Hillshade raster that will serve as the map background.

7. Enter a Hillshade Name. 
8. By default, SolVES locates the State polygon feature class in the source file geodatabase to use as the Locator Boundary for the locator map on the SolVES map layout. Alternatively, you may select the Counties feature layer to serve as the boundary or any other suitable polygon feature layer you have loaded into the source file geodatabase.

9. Enter a Locator Boundary Name (for example, the name of the State or States in which the study area is located).

10. Select OK.

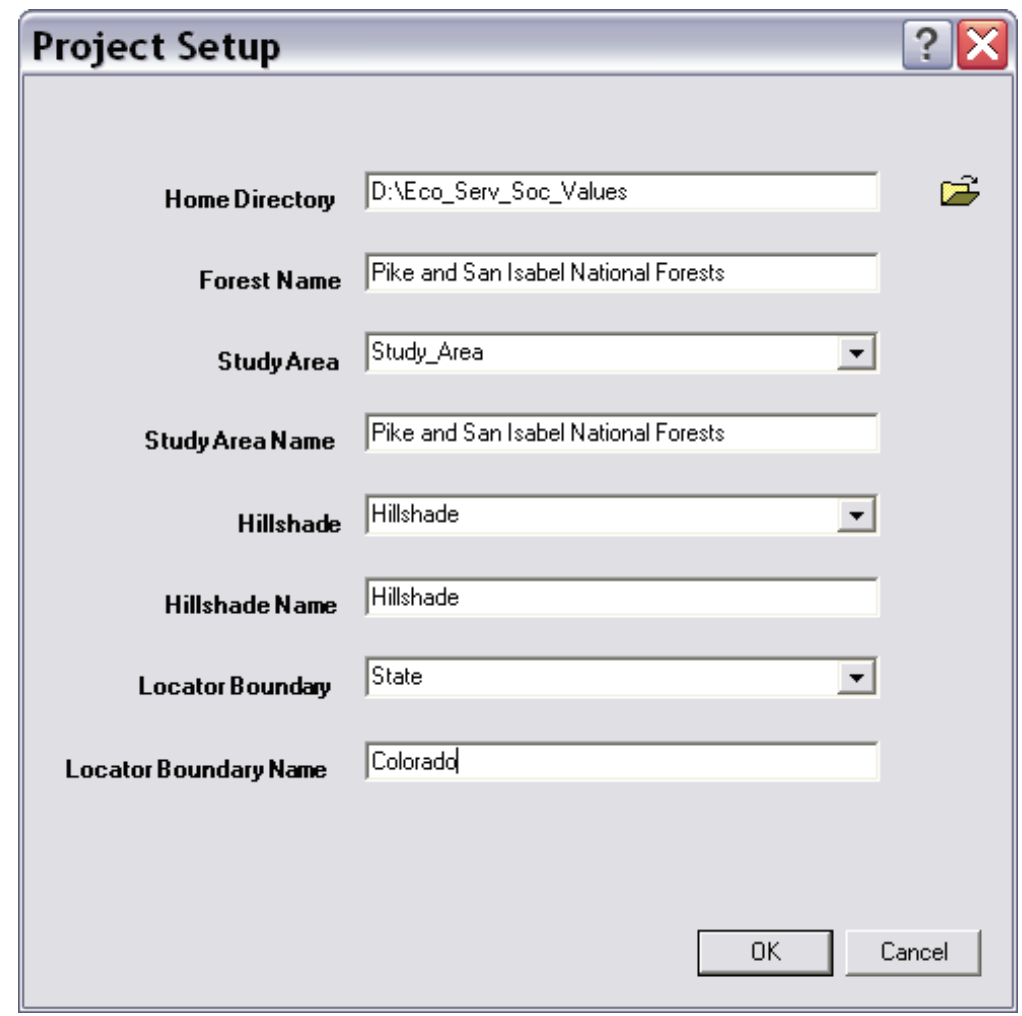

Figure 20. A completed Project Setup form. 
11. At this point, a map layout is generated as shown below (fig. 21). The Ecosystem Services Social Values Model may now be run followed by the Value Mapping Model, or alternatively, the Value Transfer Mapping Model may be run.

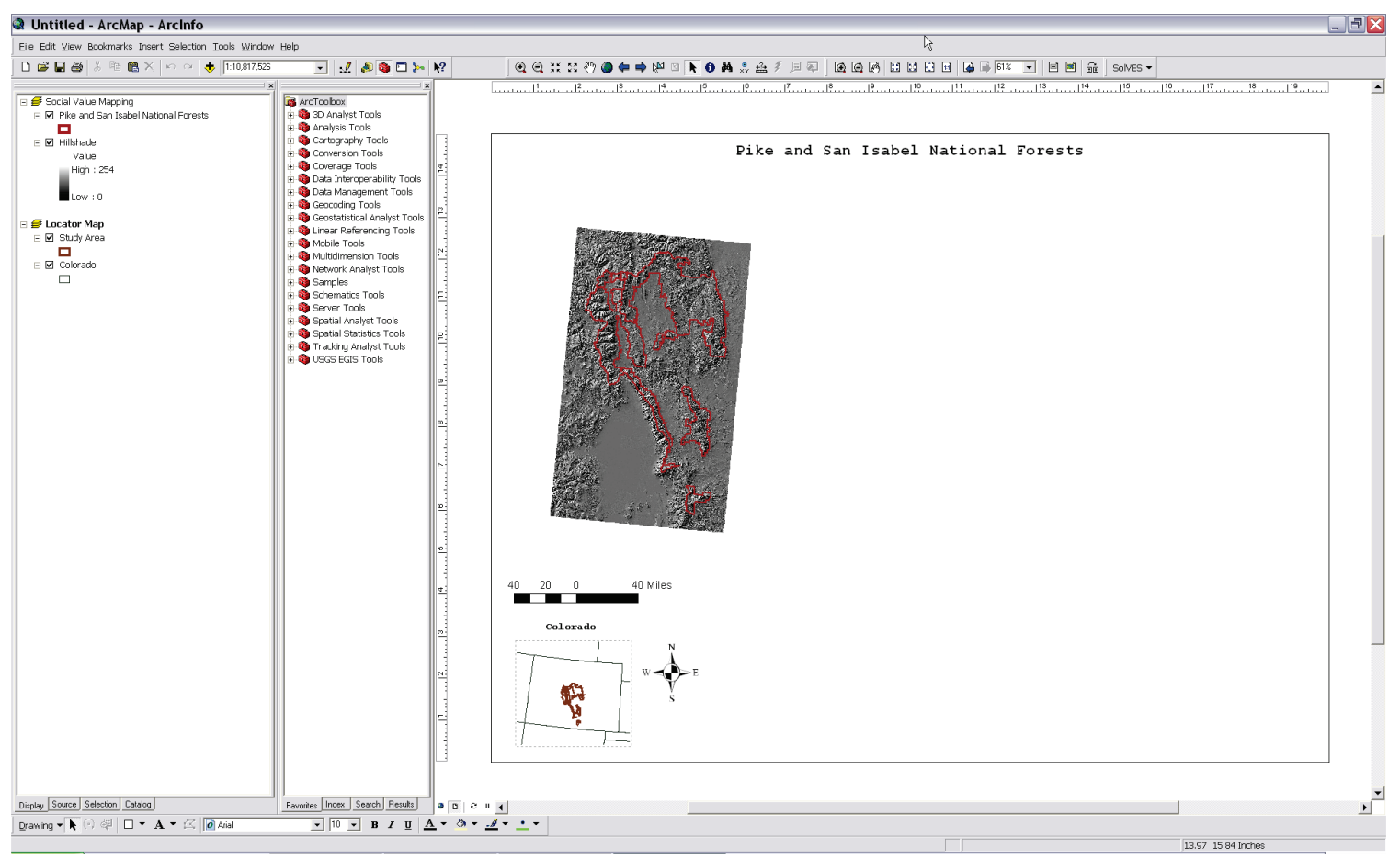

Figure 21. A map layout generated during project setup.

\section{Ecosystem Services Social Values Model}

1. The Ecosystem Services Social Values Model is run by selecting Value Mapping and then Ecosystem Services Social Values Model from the toolbar as shown below (fig. 22).

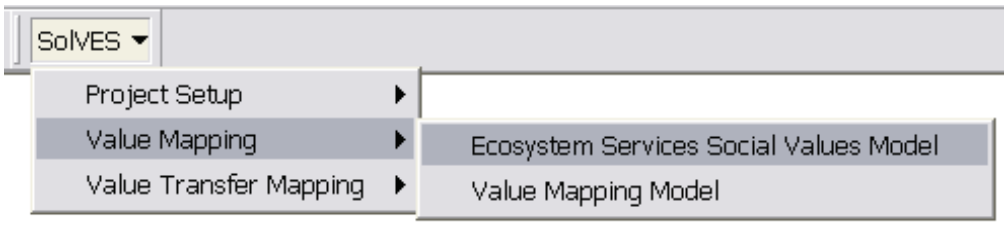

Figure 22. Selecting the Ecosystem Services Social Values Model.

2. The form that opens as shown below (fig. 23) provides a description of the model in the help window. If the help window is not visible, click on the Show Help/Hide Help button at the bottom of the form. More detailed information describing each model can also be accessed by clicking on the Tool Help button. 


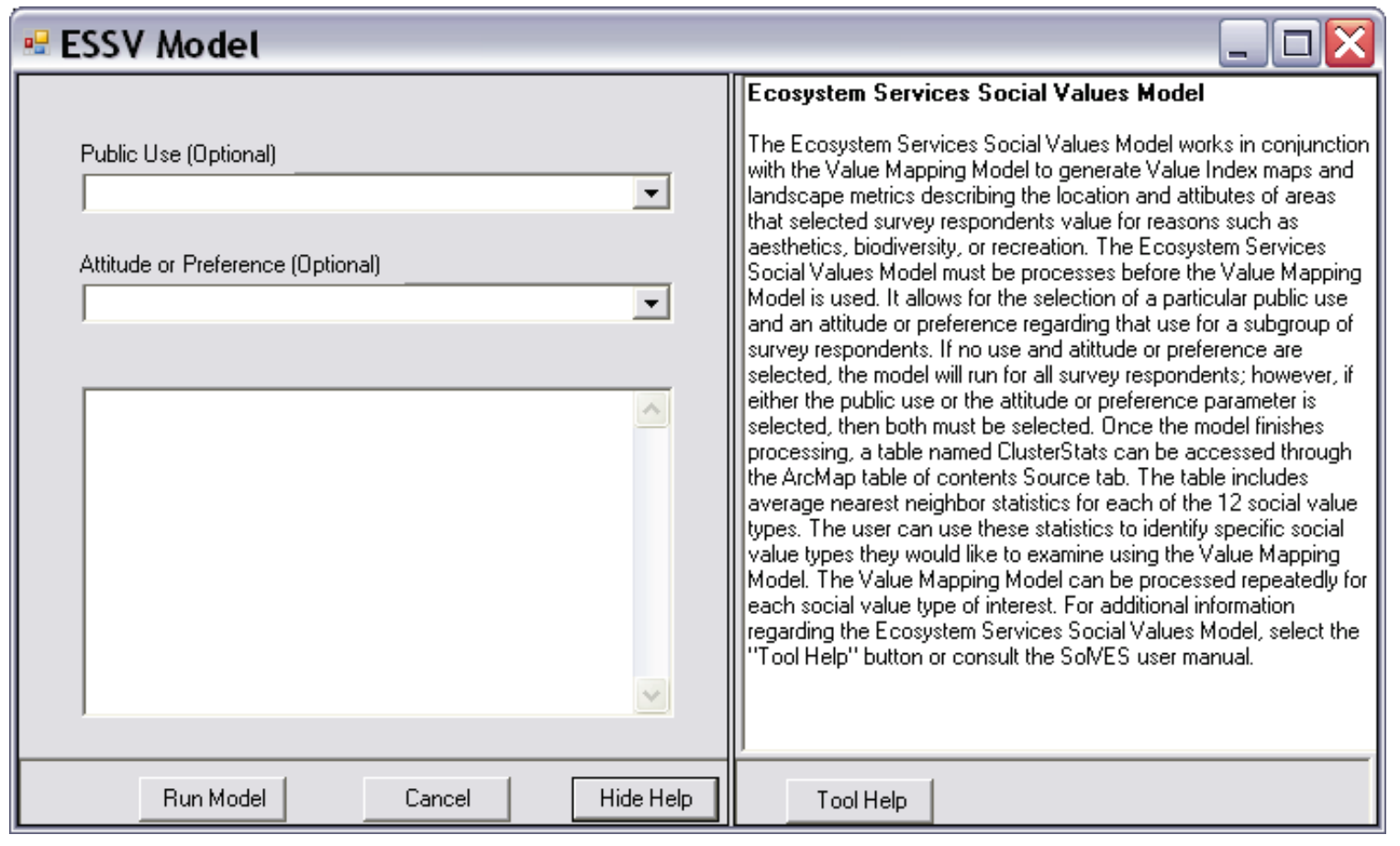

Figure 23. Parameter selection form for the Ecosystem Services Social Values Model.

3. When the Public Use dropdown box is selected, a list of available public uses is displayed in the help window to assist with selecting a public use for analysis. Make your selection from these choices.

4. Select the Attitude or Preference dropdown box and choose the desired attitude or preference regarding the selected use.

5. Select OK and the model will process as shown below (fig. 24). Please note that the ArcMap document layout will not be visible while the model is processing.

IMPORTANT NOTE: The Public Use and Attitude or Preference parameters have been designated as optional so that social value maps may also be generated for all survey respondents. Please keep in mind that these parameters are conditionally optional, meaning that either both or neither of them must be selected. 


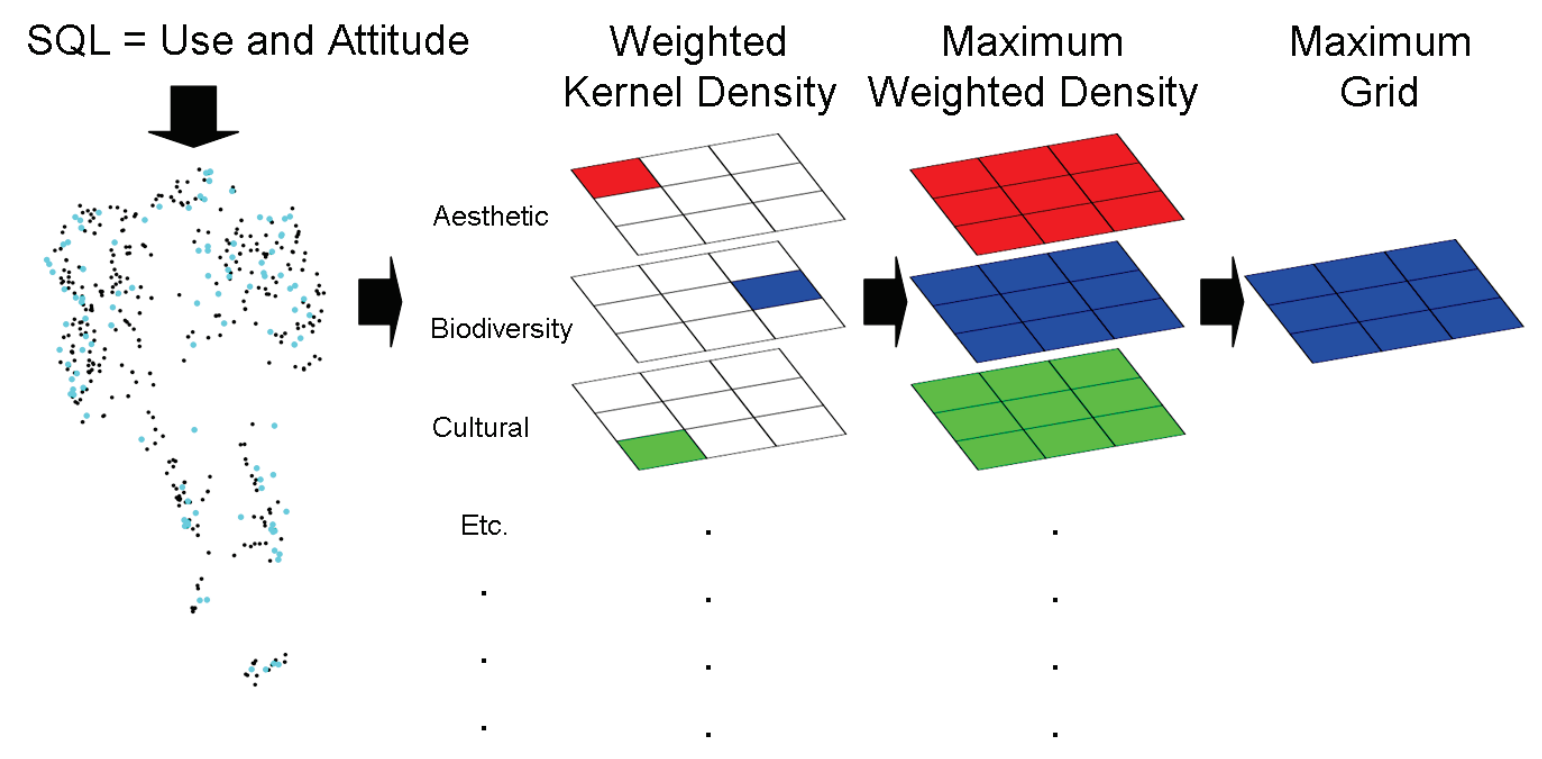

Figure 24. Ecosystem Services Social Values Model process steps.

The public-use and attitude parameters are converted to a SQL statement, which is then used to select the mapped survey points from that subgroup of survey respondents. Kernel density surfaces weighted by the total value amount allocated to each social value type by the survey subgroup are generated for each of the 12 social value types. The maximum density value for each social value type (as indicated by colored grid cells in fig. 24) is identified, and a constant grid composed entirely of that value is generated. Finally, the constant grid containing the highest overall value is selected from among the 12 social value types. This "Maximum Grid" will be used by the Value Mapping Model to normalize the kernel density surfaces and ultimately generate a Value Index map.

IMPORTANT NOTE: The kernel density surfaces are generated following a methodology similar to that of Alessa and others (2008) in their mapping of social-ecological hotspots on Alaska's Kenai Peninsula. As opposed to simple point density, the basis of kernel density is a quadratic kernel function (Silverman, 1986). This function defines a smoothly curved surface fit over each point and extending out to a defined search radius. The volume below each surface is equal to the weight assigned to the point. Given the similar spatial extents of the two study areas, the kernel density search-radius parameter of 5,000 m used by Alessa and others (2008) was also used for the initial development of SolVES. The kernel density output cell-size parameter was set to $450 \mathrm{~m}$ as determined from the approximate scale of the original survey maps, 1:400,000 to 1:500,000. It was assumed that survey respondents could resolve the locations they marked on the maps to at best $450 \mathrm{~m}$. This was near the 500-m cell size selected by Alessa and others (2008) but provided for cells that would align with $15 \mathrm{x}$ 15 arrays of the $30-\mathrm{m}$ rasters from which landscape metrics are calculated. The search-radius and output cell-size parameters are not adjustable in the current version of SolVES. Obviously, this might affect SolVES results as it is used in study areas of varying sizes. Particularly, the resolution of the spatial and statistical results may be at larger or smaller scales than desired. Future versions of SolVES will address the need for flexibility in setting kernel density parameters.

To assist with the selection of social value types for further analysis by the Value Mapping Model, the Ecosystem Services Social Values Model generates average nearest neighbor statistics describing the relative dispersion, clustering, or randomness of the mapped points. Following the example of Clement (2006) and Brown and others (2002), the point data are subjected to Completely Spatially Random (CSR) hypothesis testing through the calculation of average nearest neighbor 
statistics. The ratio of the observed distance between points to the expected distance between points, or $\mathrm{R}$ value, along with each $\mathrm{R}$ value's number of standard deviations from the mean, or Z score, identify point patterns for which statistically significant clustering is observed. Such clustering is described by $R$ values of less than 1 having highly negative $Z$ scores. These statistics can be used to limit a user's focus to social value types occupying locations with specific levels of significance on the landscape as determined by the selected survey subgroup. Users may, of course, for various reasons want to also examine some of the more randomly distributed social value types, but the average nearest neighbor statistics provide an initial indication of the social value maps that will likely display the most intensely valued hotspots as measured by the Value Index.

To view these statistics, select the Source tab from the ArcMap table of contents and then locate and open the "ClusterStats" table. As shown below (fig. 25), the table includes the name of each social value type along with its number of mapped points (N_Count), its R value (R_Score), and its Z score (Z_Score).

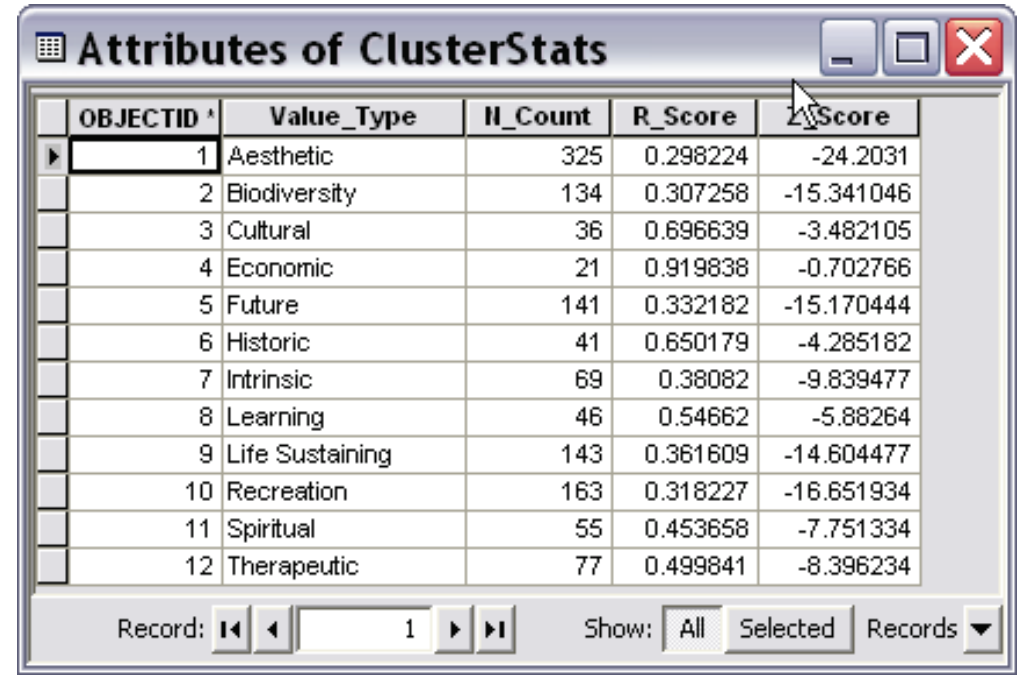

Figure 25. Average nearest neighbor statistics calculated by the Ecosystem Services Social Values Model.

\section{Value Mapping Model}

After the Ecosystem Services Social Value Model has processed a survey subgroup, the Value Mapping Model may be repeatedly run for any number of the social value types.

1. The model is run by selecting Value Mapping and Value Mapping from the SolVES toolbar as shown below (fig. 26).

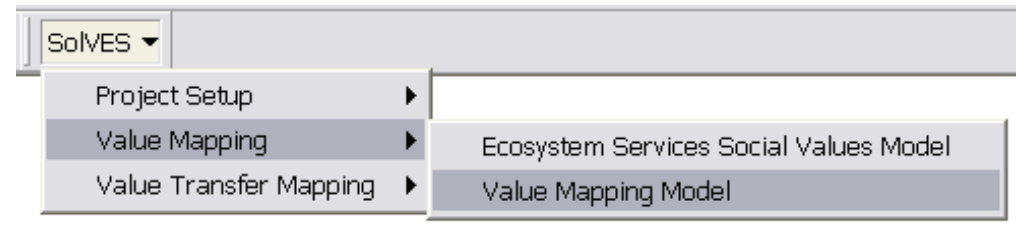

Figure 26. Selecting the Value Mapping Model. 
2. The Value Mapping Model form as shown below (fig. 27) is then opened providing a dropdown box for selecting social value types and a help window describing the model.

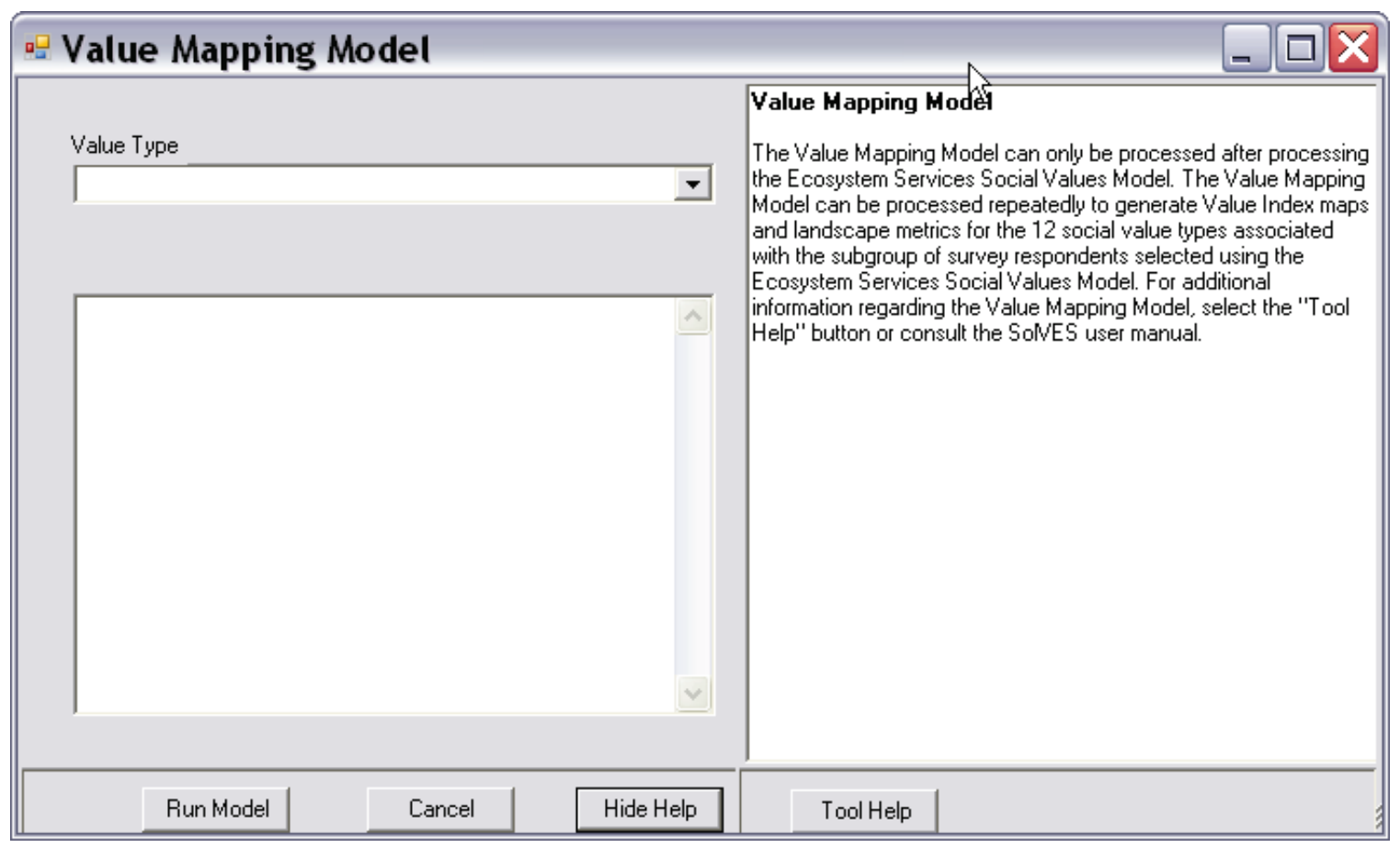

Figure 27. Parameter selection form for the Value Mapping Model.

3. Upon selection of the Value Type dropdown box, a list of the available social value types along with their descriptions will appear in the help window.

4. Make a selection from the Value Type dropdown box and select OK. The model will process as shown below (fig. 28). Please note that the ArcMap document layout will not be visible while the model is processing. 


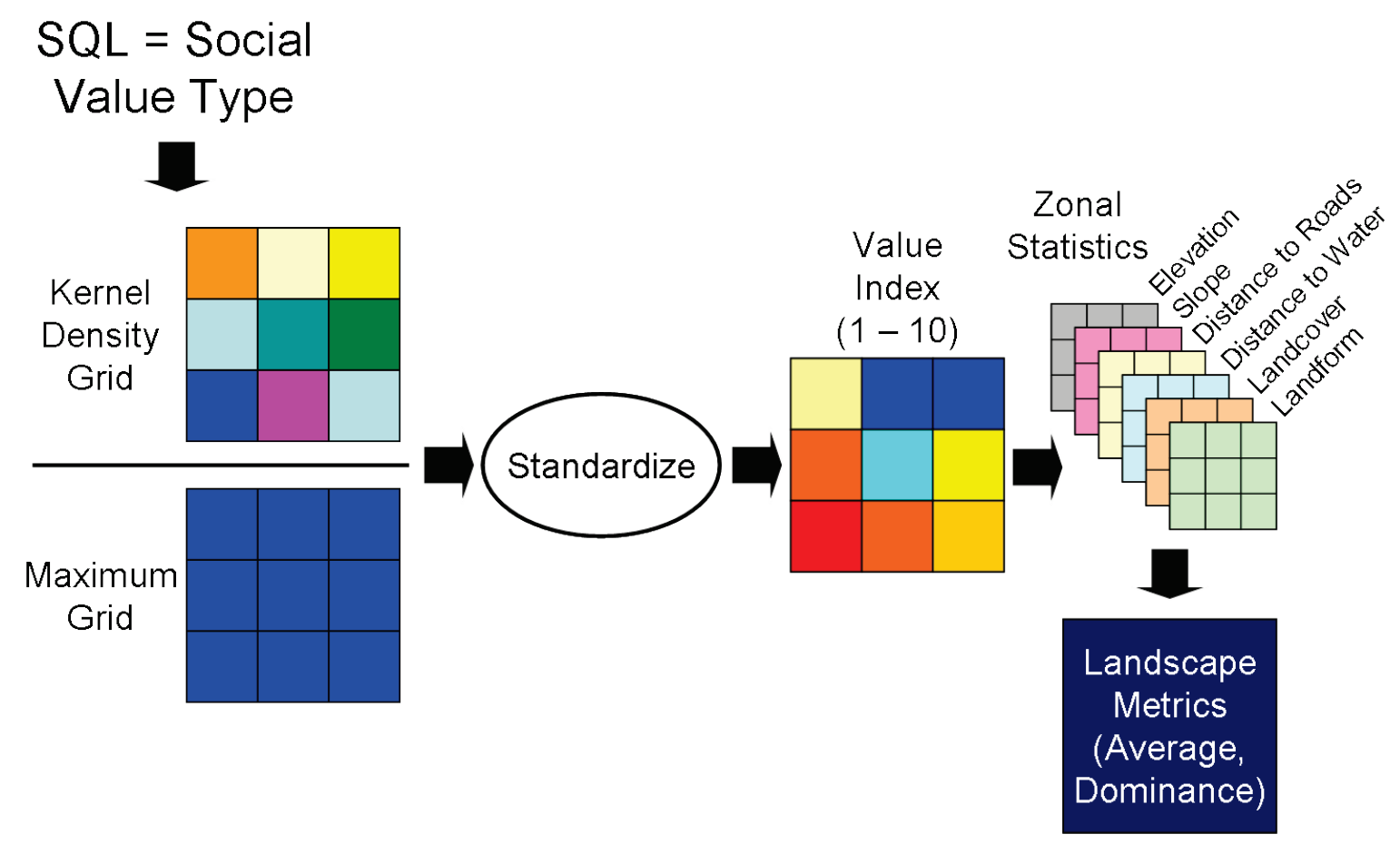

Figure 28. Value Mapping Model process steps.

The selected Value Type parameter is converted to a SQL statement that is then used to select the Kernel Density Grid that was generated for the selected social value type by the Ecosystem Services Social Values Model. The selected kernel density grid is then divided by the "Maximum Grid" generated by the Ecosystem Services Social Values Model. The normalized grid is then standardized into the 10-point Value Index integer grid, which is then added to the ArcMap layout. As a result of normalization to the Maximum Grid, the value of every cell on every weighted kernel density surface is scaled relative to the most highly valued geographic location and to the most highly valued social value type as rated by the selected survey subgroup. The Value Index can be used to measure and compare the magnitude of value differences within and among survey subgroups as well as to produce social value maps and associated landscape metrics. The higher the value attained on the Value Index by a social value type within a survey subgroup, the more highly it is valued by that survey subgroup. Within a single survey subgroup, a social value type that attains a 10 on the Value Index corresponds to one or more locations within the study area where that survey subgroup values that social value type more highly than at any other location and more highly than any of the other value types regardless of location. For social value types that attain less than a 10 on the Value Index, the maximum index value that they do attain $(9,8,7$, and so forth) corresponds to locations where that social value type is valued more highly than at any other location. Among survey subgroups, the maximum attained index value can be used to make some general comparisons regarding the relative value each subgroup places on a social value type.

The Value Index is also used as a zone-defining layer to calculate zonal statistics from the landscape data layers. These statistics are presented as the landscape metrics in the ArcMap layout. An example of Value Mapping Model output is shown below (fig. 29). 


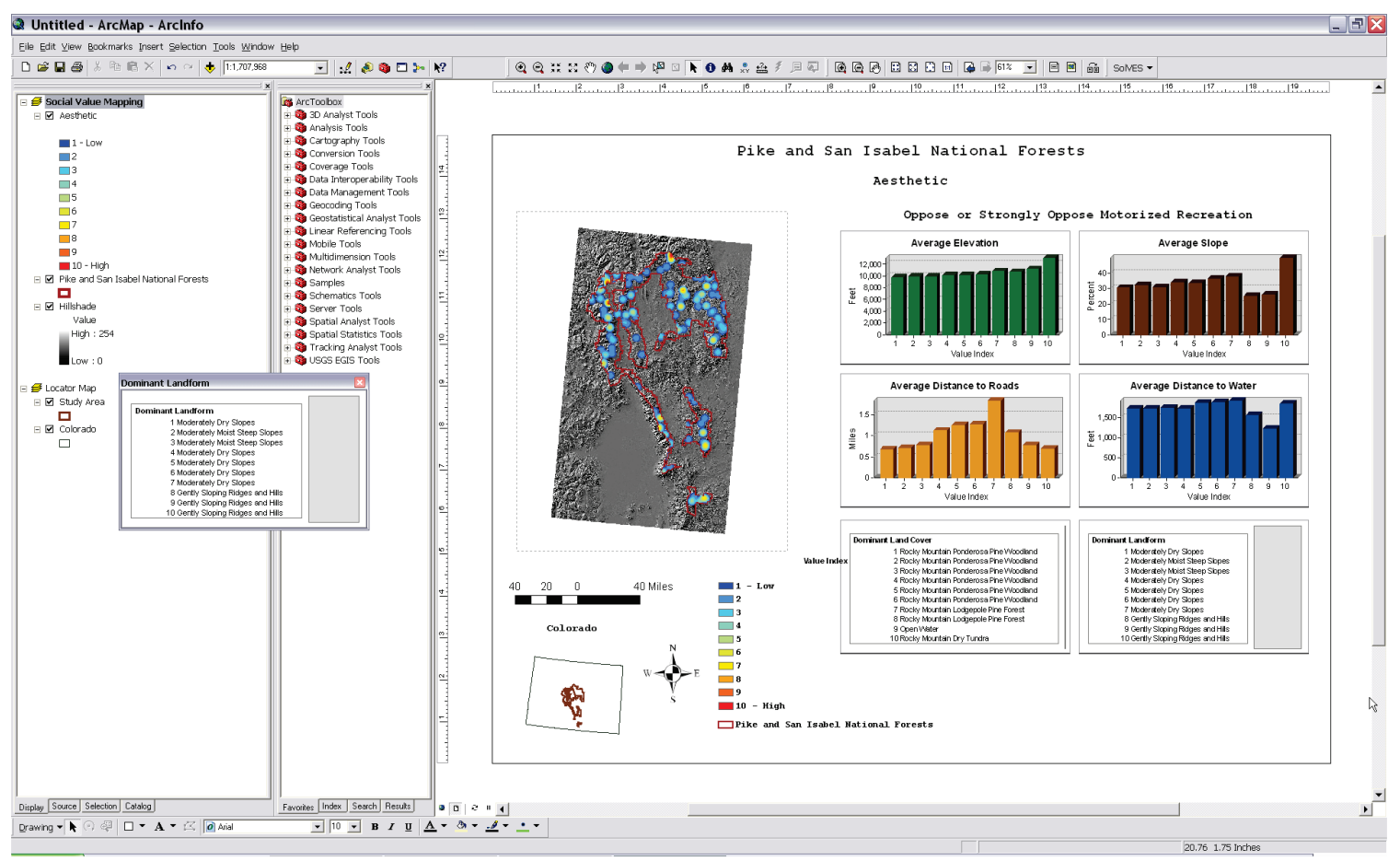

Figure 29. Sample output from the Value Mapping Model.

IMPORTANT NOTE: As the Value Mapping Model generates each social value map and landscape metric layout, access the ArcMap File menu, select Export Map, and select a file format such as PDF or JPG to save a copy of the map layout. You should provide each exported file with a unique name describing the survey subgroup and social value type it includes for future reference. The map layout may be manually rearranged prior to exporting to better fit the content and orientation of the output from various study areas. The ArcMap document file itself (.mxd) should not be saved with the intent of preserving a specific map layout since SolVES currently overwrites the source tables for the landscape metrics each time the model is run.

\section{Value Transfer Mapping Model}

The Value Transfer Mapping Model can be used when primary survey data are unavailable for a study area or to complement existing survey data. It relies on regression coefficients generated by an analysis of the results produced from applying SolVES to the PSI survey data. These coefficients are stored in the Coefficients table in the source file geodatabase.

1. The Value Transfer Mapping Model is accessed by selecting Value Transfer Mapping and Value Transfer Mapping from the SolVES toolbar (fig. 30). 


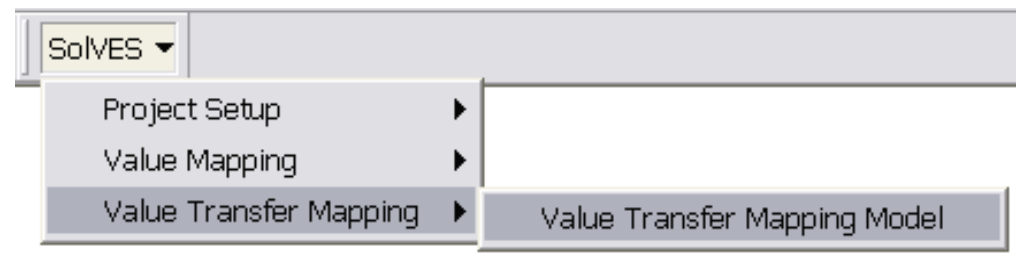

Figure 30. Selecting the Value Transfer Mapping Model.

Like the other models, the form that opens provides a series of dropdown boxes for selecting Public Use, Attitude or Preference, and Value Type parameters along with a help window to provide a description of the model as well as each parameter (fig. 31).

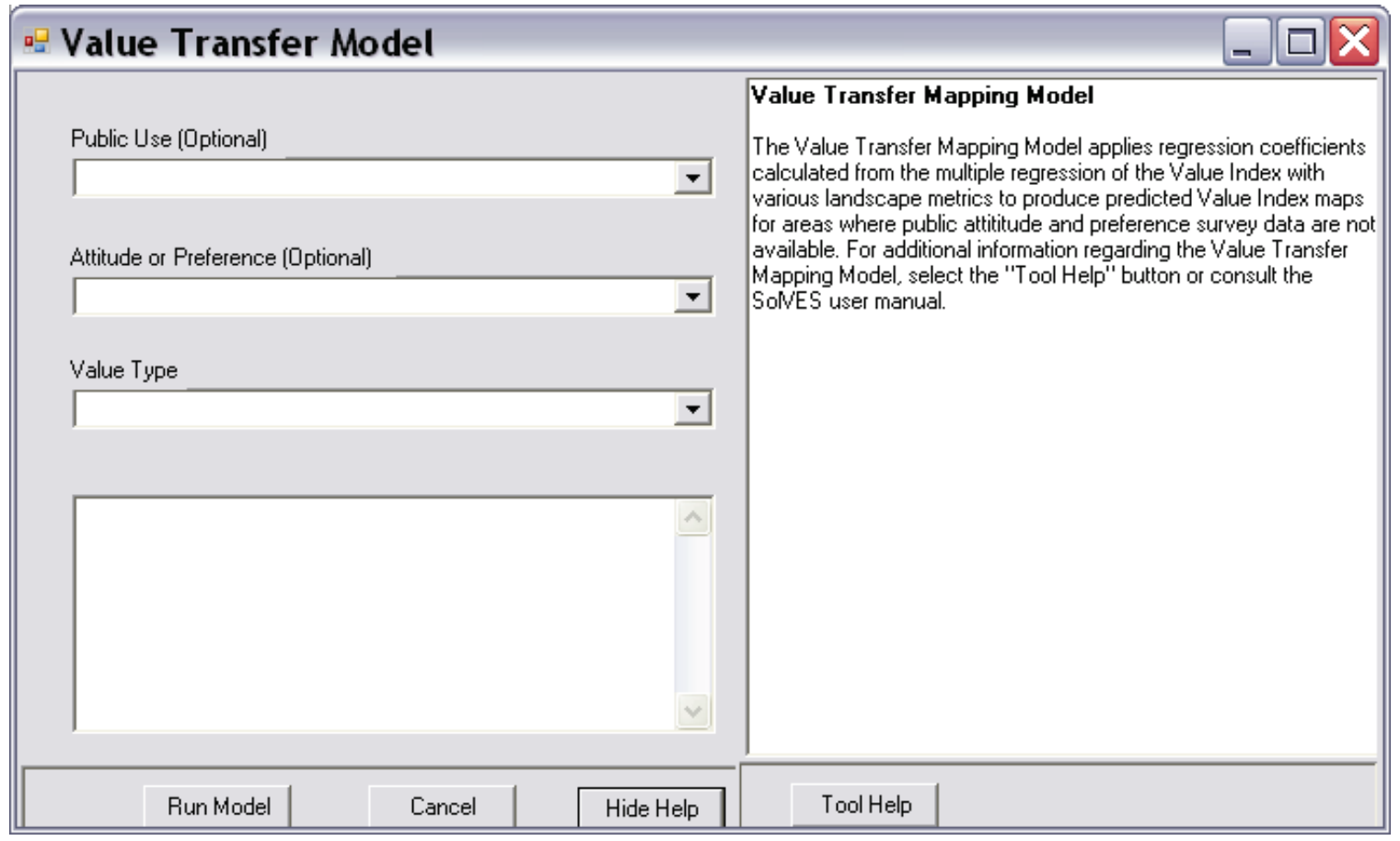

Figure 31. Parameter selection form for the Value Transfer Mapping Model.

2. After making your selections for each of the three parameters (or just the Value Type parameter if a social value map for all survey respondents is desired), select OK. The model will process as shown below (fig. 32). Please note that the ArcMap document layout will not be visible while the model is processing. 


\section{$\mathrm{SQL}=$ Use, Attitude, and Social Value Type}
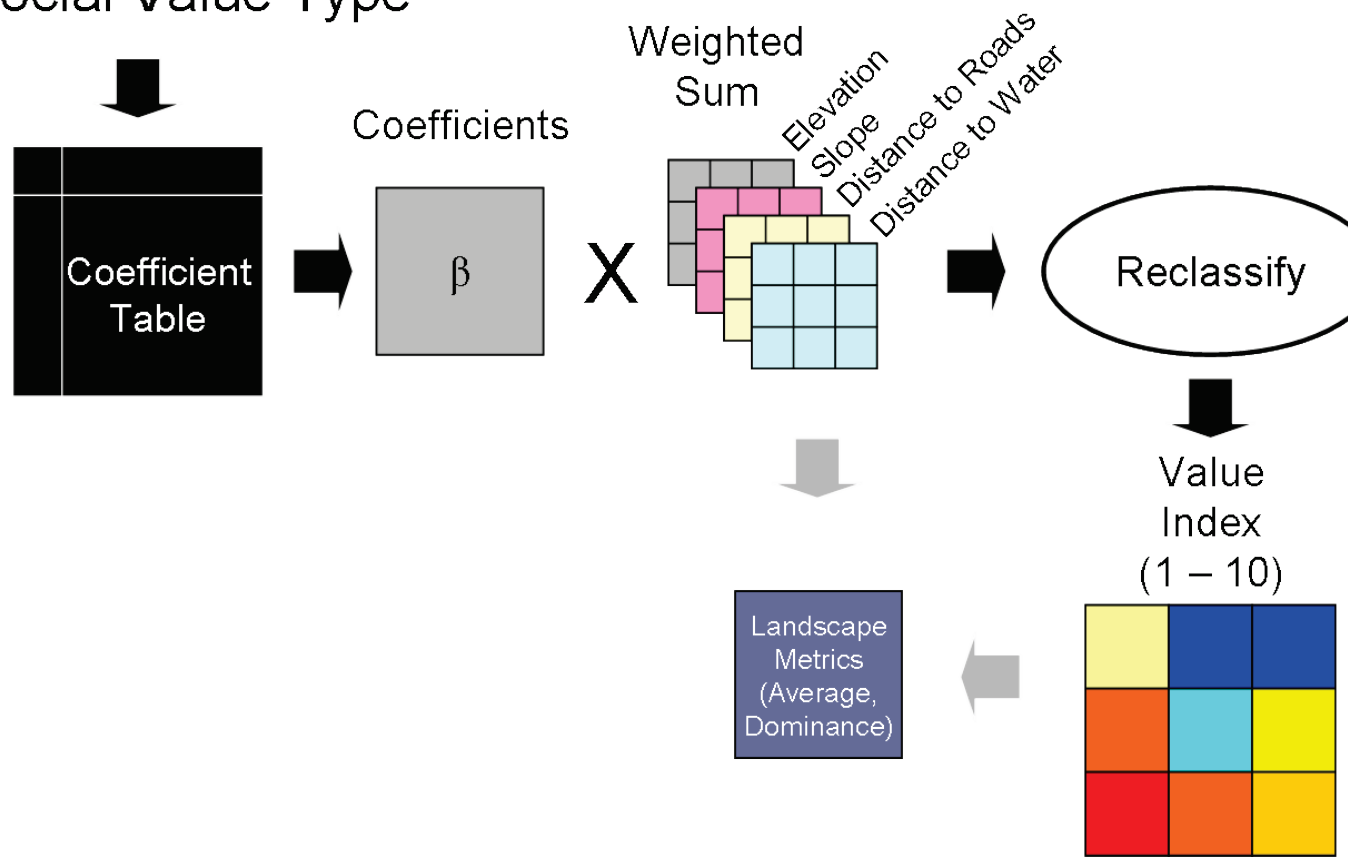

Figure 32. Value Transfer Mapping Model process steps.

The selected parameters are converted to a SQL statement that is then used to select the matching coefficients from the Coefficients table. The coefficients are then applied to their respective landscape data layers by a weighted sum calculation. The resulting grid is then reclassified into the 10point Value Index grid, which is then displayed in the ArcMap layout and used to calculate landscape metrics. An example of the Value Transfer Mapping Model output is shown below (fig. 33). In this example, SolVES was applied in Grand County, Colorado, immediately north of the PSI from which the coefficients were derived. 


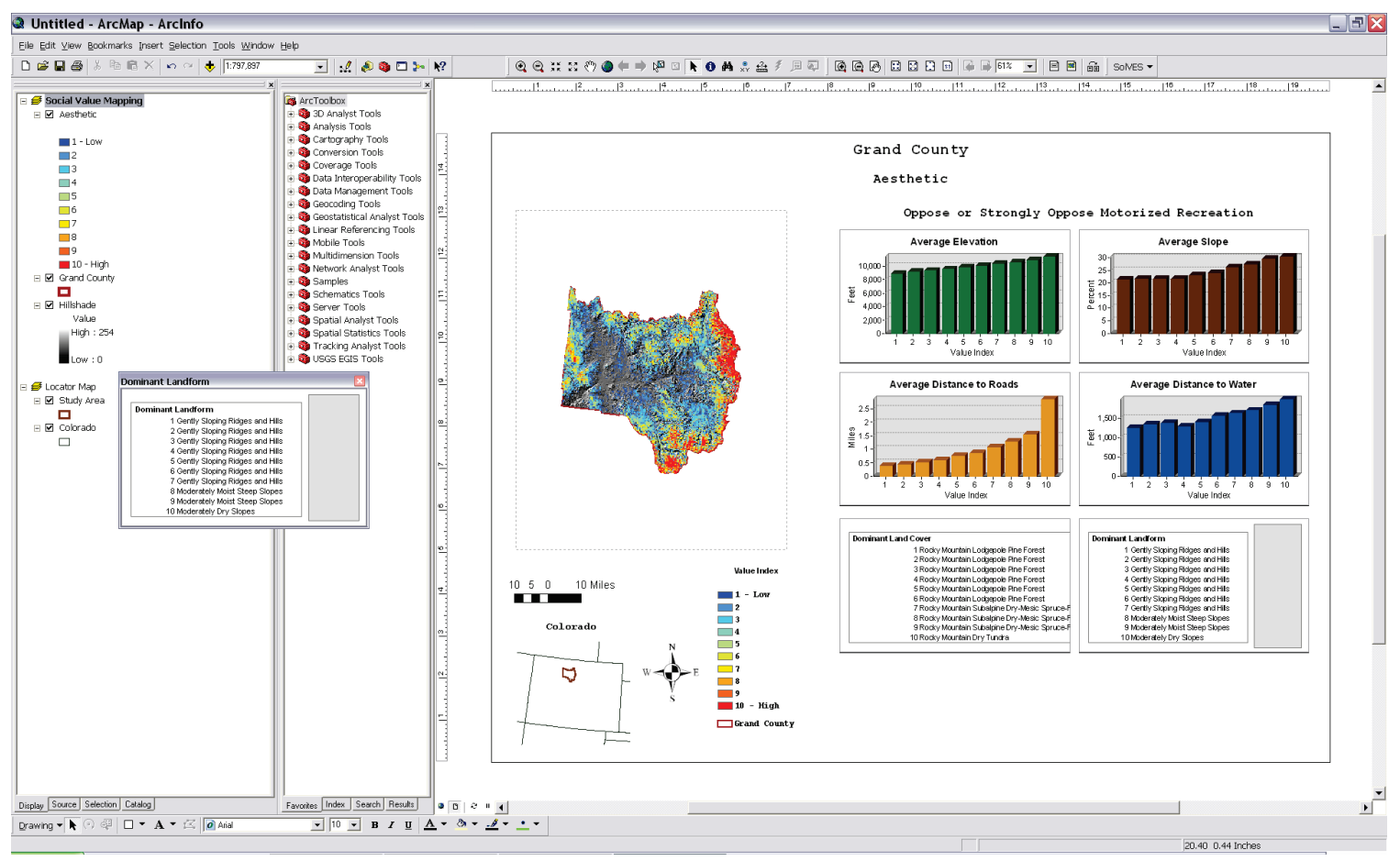

Figure 33. Sample output from the Value Transfer Mapping Model.

IMPORTANT NOTE: As the Value Transfer Mapping Model is processed for each social value type to produce a social value map and landscape metric layout, access the ArcMap File menu, select Export Map, and select a file format such as PDF or JPG to save a copy of the map layout. You should provide each exported file with a unique name describing the survey subgroup and social value type it includes for future reference. The ArcMap document file itself (.mxd) should not be saved with the intent of preserving a specific map layout since SolVES currently overwrites the source tables for the landscape metrics each time the model is run.

IMPORTANT NOTE: The current version of SolVES calculates landscape metrics for elevation, slope, distance to roads, and distance to water. It should be kept in mind, however, that these data were included in the multiple regressions that generated the coefficients the Value Transfer Mapping Model uses to produce social value maps. Consequently, there is likely little new information to be obtained from the metrics for these landscape data layers. Since the landcover and landform metrics were not included in these multiple regressions, the dominant landcover and landform metrics generated by the Value Transfer Mapping Model might prove more informative.

IMPORTANT NOTE: The reclassification of the weighted sum grid to produce the Value Index will likely result in a range of values that is larger than that of the 10-point scale being collapsed into the Value Index. Any negative values are reclassified to 0 , whereas any values greater than 10 are reclassified as 10. Additionally, the current method used by the Value Transfer Mapping Model does not allow for the same type of relative value comparisons between social value types and survey subgroups as the other models since the maximum index value is always 10 . As future versions of SolVES are developed, alternatives for generating the Value Index for predicted social value maps will be investigated to take these factors into account. 


\section{Advanced Options}

\section{Adding or Changing Regression Coefficients}

All regression coefficients stored in the Coefficients table and used by the Value Transfer Mapping Model were derived from the PSI survey data that were the subject of a case study analysis of SolVES output. Consequently, the coefficients are most appropriate for performing value transfer to study areas with physical and social similarities to the PSI. The existing coefficients were generated using the Microsoft ${ }^{\circledR}$ Office Excel 2003 Analysis ToolPak.

Users may wish to add to or make changes to the Coefficients table. This may be the result of factors such as having regression coefficients derived from primary survey data from other study areas, using more sophisticated software to complete the statistical analyses, or simply wanting to explore how changes to regression coefficients affects the output of the Value Transfer Mapping Model. It is advised, however, that you make a backup copy of the Coefficients table prior to making any changes.

The Coefficients table is illustrated in the section, Source File Geodatabase Format (see fig.12). In addition to the system-updated OBJECTID field, the table includes the fields described below (table 11).

Table 11. Formatting requirements for the Coefficients table.

\begin{tabular}{|c|c|c|}
\hline Field Name & Field Data Type & Field Description \\
\hline PUBLIC_USE & String & $\begin{array}{l}\text { The public use related to the regression coefficients. Values } \\
\text { must be entered exactly as they are listed in the section, } \\
\text { Survey Data (see table 1). If the coefficients represent all } \\
\text { surveys, then "All Surveys" must be entered in the field. }\end{array}$ \\
\hline VALUE_TYPE & Long Integer & $\begin{array}{l}\text { The social value type related to the regression coefficients. } \\
\text { Values must be entered as an integer from } 1 \text { to } 12 \text { as } \\
\text { described in the section, Source File Geodatabase Format } \\
\text { (see table 8). }\end{array}$ \\
\hline ELEV & Double & $\begin{array}{l}\text { The regression coefficient derived from the DEM landscape } \\
\text { data layer. Enter } 0 \text { if this value was not included in the } \\
\text { multiple regression. }\end{array}$ \\
\hline SLOPE & Double & $\begin{array}{l}\text { The regression coefficient derived from the Slope landscape } \\
\text { data layer. Enter } 0 \text { if this value was not included in the } \\
\text { multiple regression. }\end{array}$ \\
\hline DTR & Double & $\begin{array}{l}\text { The regression coefficient derived from the DTR landscape } \\
\text { data layer. Enter } 0 \text { if this value was not included in the } \\
\text { multiple regression. }\end{array}$ \\
\hline DTW & Double & $\begin{array}{l}\text { The regression coefficient derived from the DTW landscape } \\
\text { data layer. Enter } 0 \text { if this value was not included in the } \\
\text { multiple regression. }\end{array}$ \\
\hline INT & Double & The intercept term of the multiple regression equation. \\
\hline ADJ_RSQ & Double & $\begin{array}{l}\text { The adjusted R-squared value of the multiple regression } \\
\text { equation. This field is not currently required by SolVES. }\end{array}$ \\
\hline ATTITUDE & String & $\begin{array}{l}\text { The attitude or preference for the associated public use. } \\
\text { Allowable values included "Favor or Strongly Favor" and } \\
\text { "Oppose or Strongly Oppose". If the coefficients represent } \\
\text { all surveys, then "All Surveys" must be entered in the field. }\end{array}$ \\
\hline
\end{tabular}

Values in the Coefficient table may be changed and additional records may be added by accessing the table through ArcMap and using the Editor Toolbar to complete the changes or additions. 
Alternatively, if adding multiple new records, the Loading function described in the section, Importing and Loading Data to the Source File Geodatabase, may also be used.

IMPORTANT NOTE: Only one set of coefficients may be entered for every unique combination of public use, attitude, and social value type (for example, if a record exists where PUBLIC_USE $=$ "Motorized Recreation," VALUE_TYPE = 1, and ATTITUDE = "Oppose or Strongly Oppose," another record with these same value types may not be entered; coefficient values would need to be changed instead). 


\section{Troubleshooting}

\section{Error Messages}

Error messages might be encountered through the course of using SolVES. Trapping and handling these errors will be an ongoing activity through the course of developing future versions of SolVES. Frequent errors encountered to date are described below.

- Improper Selection of Model Parameters - When processing the Ecosystem Services Social Values Model or the Value Transfer Mapping Model, either both the Public Use and Attitude or Preference parameters must be selected or neither must be selected. If either is selected when the other is not, the model will generate the error highlighted below (fig. 34). If such an error should occur, select Close and attempt to run the model again after making sure the parameters are properly selected.

\section{SoIVES}

ERROR: Both the public use and the attitude or preference parameters must be selected if either is selected.

$$
\text { OK }
$$

Figure 34. Improper selection of model parameters error message.

- No Coefficients Available - When processing the Value Transfer Mapping Model, situations may be encountered where coefficients for a particular survey subgroup or social value type are not available in the Coefficients table. An error message similar to the one highlighted below will be generated (fig. 36). The reason for the absence of coefficients is that the criteria applied in the original case study analysis of the PSI and relied upon for the initial development of SolVES resulted in survey subgroups and social value types for which there were insufficient or otherwise unusable data for performing the regression analyses necessary to produce the regression coefficients. To resolve the error, select Close and run the Value Transfer Mapping Model with different parameters selected.

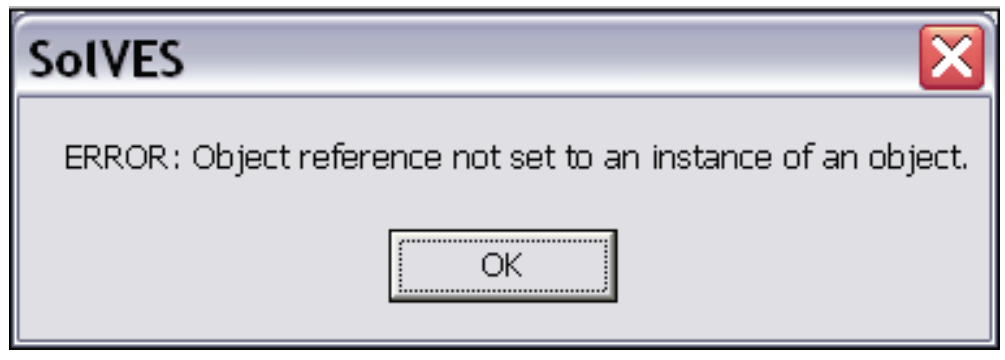

Figure 35. No coefficients available error message.

Additional, unaccounted-for errors may occur when using SolVES. Generally, these errors should be resolvable by selecting Close and running the model with different criteria. If this is not sufficient, additional steps might include the following: 
- Completely close and restart ArcMap. Then attempt to run the SolVES models again.

- Delete any existing data from the Results and Scratch folders through ArcCatalog. Deleting files through Windows Explorer is not advised. If you want to retain any of these data, move them out of the Results or Scratch folders or copy them to another location before deleting the remaining contents of the Results and Scratch folders. 


\section{Acknowledgments}

SolVES was developed by the USGS Rocky Mountain Geographic Science Center (RMGSC) in collaboration with Dr. Jessica M. Clement of the Department of Forest, Rangeland and Watershed Stewardship at Colorado State University. Dr. Clement made available to the RMGSC the Pike and San Isabel National Forests survey data (Clement and Cheng, 2006) that served as the basis for the initial development of SolVES. Additionally, her continued contributions are invaluable to the success of SolVES.

Special thanks are also extended to our colleagues at the RMGSC who reviewed the SolVES application, data, and documentation including Jay Diffendorfer, Catherine Costello, and Roger Compton. 


\section{References Cited}

Alessa, L.N., Kliskey, A.A., and Brown, G., 2008, Social-ecological hotspots mapping: a spatial approach for identifying coupled social-ecological space: Landscape and Urban Planning, v. 85, p. 27 39.

Brown, G., 2005, Mapping spatial attributes in survey research for natural resource management: methods and applications: Society and Natural Resources, v. 18, p. 17-39.

Brown, G., and Alessa, L., 2005, A GIS-based inductive study of wilderness values: International Journal of Wilderness, v. 11, no. 1, p. 14-18.

Brown, G., and Reed, P., 2000, Validation of a forest values typology for use in national forest planning: Forest Science, v. 46, no. 2, p. 240-247.

Brown, G.G., Reed, P., and Harris, C.C., 2002, Testing a place-based theory for environmental evaluation: an Alaska case study: Applied Geography, v. 22, p. 49-76.

Brown, G., Smith, C., Alessa, L., and Kliskey, A., 2004, A comparison of perceptions of biological value with scientific assessment of biological importance: Applied Geography, v. 24, p. 161-180.

Clement, J.M., 2006, Spatially explicit values on the Pike and San Isabel National Forests in Colorado: Fort Collins, Colorado State University, Ph.D. dissertation, ProQuest/UMI, AAT 3246268.

Clement, J.M., and Cheng, A.S., 2006, Public values and preferences regarding forest uses and management on the Pike and San Isabel National Forests, Colorado, Survey results: Fort Collins, Colorado State University, Department of Forest, Rangeland and Watershed Stewardship.

Costanza, R., d'Arge, R., de Groot, R., Farber, S., Grasso, M., Hannon, B., Limburg, K., Naeem, S., O’Neill, R.V., Paruelo, J., Raskin, R.G., Sutton, P., and van den Belt, M., 1997, The value of the world's ecosystem services and natural capital: Nature, v. 387, p. 253-260.

Cowling, R.M., Egoh, B., Knight, A.T., O’Farrell, P.J., Reyers, B., Rouget, M., Roux, D.J., Welz, A., and Wilhelm-Rechman, A., 2008, An operational model for mainstreaming ecosystem services for implementation: PNAS, v. 105, no. 28, p. 9483-9488.

Daily, G.C., 1997, Introduction: what are ecosystem services?, in Daily, G.C., ed., Nature's services: Societal dependence on natural ecosystems: Washington, D.C., Island Press, p. 1-10.

Kumar, M., and Kumar, P., 2008, Valuation of the ecosystem services: a psycho-cultural perspective: Ecological Economics, v. 64, p. 808-819.

Millennium Ecosystem Assessment, 2003, Ecosystems and human well-being: A framework for assessment: Washington, D.C., Island Press, 245 p.

Nijkamp, P., Vindigni, G., and Nunes, P.A.L.D., 2008, Economic valuation of biodiveristy: a comparative study: Ecological Economics, v. 67, p. 217-231. 
Reed, P., and Brown, G., 2003, Values suitability analysis: a methodology for identifying and integrating public perceptions of ecosystem values in forest planning: Journal of Environmental Planning and Management, v. 46, no. 5, p. 643-658.

Silverman, B.W., 1986, Density estimation for atatistics and data analysis: New York, Chapman and Hall, 176 p.

Troy, A., and Wilson, M.A., 2006, Mapping ecosystem services: practical challenges and opportunities in linking GIS and value transfer: Ecological Economics, v. 60, p. 435-449.

U.S. Department of Agriculture (USDA), 2008, Counting all that matters: recognizing the value of ecosystem services: USDA Forest Service, Pacific Northwest Research Station, PNW Science Update $16,11 \mathrm{p}$.

Watts, R.D., Compton, R.W., McCammon, J.H., Rich, C.L., Wright, S.M., Owens, T., and Ouren, D.S., 2007, Roadless space of the conterminous United States: Science, v. 316, p. 736-738. 